\title{
Adverse Effects, Transformation and Channeling of Aflatoxins Into Food Raw Materials in Livestock
}

\begin{abstract}
Ferenc Peles ${ }^{1}$, Péter Sipos ${ }^{2 *}$, Zoltán Györi ${ }^{2}$, Walter P. Pfliegler ${ }^{3}$, Federica Giacometti ${ }^{4}$, Andrea Serraino ${ }^{4}$, Giampiero Pagliuca ${ }^{4}$, Teresa Gazzotti ${ }^{4}$ and István Pócsi ${ }^{3}$

${ }^{1}$ Institute of Food Science, Faculty of Agricultural and Food Sciences and Environmental Management, University of Debrecen, Debrecen, Hungary, ${ }^{2}$ Institute of Nutrition, University of Debrecen, Debrecen, Hungary, ${ }^{3}$ Department of Molecular Biotechnology and Microbiology, Institute of Biotechnology, Faculty of Science and Technology, University of Debrecen, Debrecen, Hungary, ${ }^{4}$ Department of Veterinary Medical Sciences, University of Bologna, Bologna, Italy
\end{abstract}

Aflatoxins are wide-spread harmful carcinogenic secondary metabolites produced by Aspergillus species, which cause serious feed and food contaminations and affect farm animals deleteriously with acute or chronic manifestations of mycotoxicoses. On farm, both pre-harvest and post-harvest strategies are applied to minimize the risk of aflatoxin contaminations in feeds. The great economic losses attributable to mycotoxin contaminations have initiated a plethora of research projects to develop new, effective technologies to prevent the highly toxic effects of these secondary metabolites on domestic animals and also to block the carry-over of these mycotoxins to humans through the food chain. Among other areas, this review summarizes the latest findings on the effects of silage production technologies and silage microbiota on aflatoxins, and it also discusses the current applications of probiotic organisms and microbial products in feeding technologies. After ingesting contaminated foodstuffs, aflatoxins are metabolized and biotransformed differently in various animals depending on their inherent and acquired physiological properties. These mycotoxins may cause primary aflatoxicoses with versatile, species-specific adverse effects, which are also dependent on the susceptibility of individual animals within a species, and will be a function of the dose and duration of aflatoxin exposures. The transfer of these undesired compounds from contaminated feed into food of animal origin and the aflatoxin residues present in foods become an additional risk to human health, leading to secondary aflatoxicoses. Considering the biological transformation of aflatoxins in livestock, this review summarizes (i) the metabolism of aflatoxins in different animal species, (ii) the deleterious effects of the mycotoxins and their derivatives on the animals, and (iii) the major risks to animal health in terms of the symptoms and consequences of acute or chronic aflatoxicoses, animal welfare and productivity. Furthermore, we traced the transformation and channeling of Aspergillus-derived mycotoxins into food raw materials, particularly in the case of aflatoxin contaminated milk, which represents the major route of human exposure among animal-derived foods. The early and reliable detection of aflatoxins in feed, forage and primary commodities is an increasingly important issue and, therefore, the newly developed, easy-to-use qualitative and quantitative aflatoxin analytical methods are also summarized in the review.
Front Microbiol $10: 2$ doi: 10.3389/fmicb.2019.02861 


\section{INTRODUCTION}

Mycotoxins are harmful secondary metabolites produced by a variety of mold species that represent serious health risks to both humans and household animals (Beardall and Miller, 1994) and, not surprisingly, they cause both acute and chronic diseases called mycotoxicoses. The chronic pathological conditions develop over a longer period of time through the consumption of both cereals and animal products, e.g., milk, meat, and eggs. They represent a risk factor to human health directly in the food chain and through biological transformations as well. Mycotoxinogenic fungi are present mainly in small grains like wheat, barley, rye, rice, triticale, and corn (Miller, 2008; Gacem and El Hadj-Khelil, 2016; Udovicki et al., 2018) and also in different feedstuffs. In fact, aflatoxins were first discovered following a severe livestock poisoning incident in England involving turkeys (e.g., Amare and Keller, 2014; Keller, 2019). In addition, aflatoxins may also occur in peanuts, figs, pistachios, Brazil nuts and cottonseeds.

A number of Aspergillus spp. belonging to sections Flavi, Ochraceorosei and Nidulantes have the ability to produce the harmful, carcinogenic difuranocoumarin derivatives called aflatoxins (Varga et al., 2015; Chen A.J. et al., 2016; Niessen et al., 2018; Frisvad et al., 2019). Aspergillus flavus, Aspergillus parasiticus, and Aspergillus nominus are the most often detected aflatoxigenic Aspergilli in feed (Table 1). Aflatoxin producer Aspergilli are of paramount importance because the aflatoxins synthesized by them are among the strongest naturally occurring carcinogenic substances (Kumar et al., 2008). Considering their chemical structures, aflatoxins are furanocoumarin derivatives (Figure 1), of which aflatoxin $\mathrm{M}_{1}\left(\mathrm{AFM}_{1}\right)$, a hydroxylated derivative of aflatoxin $\mathrm{B}_{1}\left(\mathrm{AFB}_{1}\right)$, occurs in milk and in various dairy products (Prandini et al., 2009; Giovati et al., 2015). AFM is a distinguished target in on-going mycotoxin-related research, because $\mathrm{AFM}_{1}$ consumption may be exceptionally dangerous for children especially at younger ages (Udomkun et al., 2017; Rodríguez-Blanco et al., 2019; Ojuri et al., 2019).

The risks associated with mycotoxins have an enormous economic impact, which heavily supports the need for further research in this field (Gnonlonfin et al., 2013). The scope of future mycotoxin-linked studies should be broadened and should focus more on the prevention of mycotoxin production and the reduction of their deleterious effects. One of the major objectives of current investigations is the breeding and cultivation of novel plant varieties/hybrids more resistant to infections by mycotoxin producer fungi. Another major goal focuses on the accuracy of the storage of crops and crop products, especially silage, to control the production of mycotoxins more tightly (Driehuis et al., 2018; Ogunade et al., 2018; Glamočić et al., 2019). A further important step in mycotoxin control would be to make feeding practices more rigorous to prevent mycotoxins from entering the body of animals in the first place (Aslam et al., 2016; Shanakhat et al., 2018). Furthermore, countermeasures may also include the application of various mycotoxin binding agents mixed with the feed (De Mil et al., 2015; Vila-Donat et al., 2018). Besides agricultural and technological approaches combating aflatoxins successfully, we also need to develop more sensitive and more reliable analytical methods (Kos et al., 2016).
TABLE 1 | Aflatoxin producer Aspergillus species detected in feed.

\begin{tabular}{|c|c|c|c|}
\hline Country & Type of feed & $\begin{array}{l}\text { Isolated } \\
\text { Aspergillus } \\
\text { spp. }\end{array}$ & References \\
\hline Argentina & $\begin{array}{l}\text { Maize silage, corn } \\
\text { grains, cotton seed, } \\
\text { finished feed }\end{array}$ & $\begin{array}{l}\text { A. flavus, } A \text {. } \\
\text { parasiticus }\end{array}$ & Alonso et al., 2009 \\
\hline Argentina & Maize silage & $\begin{array}{l}\text { A. flavus, } A \text {. } \\
\text { parasiticus }\end{array}$ & $\begin{array}{l}\text { González Pereyra et al., } \\
2011\end{array}$ \\
\hline Brazil & $\begin{array}{l}\text { Concentrated feed } \\
\text { and maize silage }\end{array}$ & $\begin{array}{l}\text { A. parasiticus, } \\
\text { A. nomius }\end{array}$ & Variane et al., 2018 \\
\hline Egypt & Maize silage & A. flavus & $\begin{array}{l}\text { El-Shanawany et al., } \\
2005\end{array}$ \\
\hline France & Maize silage & A. parasiticus & Garon et al., 2006 \\
\hline Ghana & Corn grain & A. flavus & Dadzie et al., 2019 \\
\hline Indonesia & $\begin{array}{l}\text { Maize of livestock } \\
\text { feed }\end{array}$ & A. flavus & Sukmawati et al., 2018 \\
\hline Iran & $\begin{array}{l}\text { Silage, concentrate, } \\
\text { hay, TMR }\end{array}$ & A. flavus & Davari et al., 2015 \\
\hline Malaysia & Corn grains & A. flavus & Zulkifli and Zakaria, 2017 \\
\hline Malaysia & Wheat and barley & A. flavus & Reddy and Salleh, 2010 \\
\hline Pakistan & Feed samples & $\begin{array}{l}\text { A. flavus, } A \text {. } \\
\text { parasiticus }\end{array}$ & Usman et al., 2019 \\
\hline Saudi Arabia & $\begin{array}{l}\text { Animal feedstuff } \\
\text { samples }\end{array}$ & $\begin{array}{l}\text { A. flavus, } A \text {. } \\
\text { parasiticus, } A \text {. } \\
\text { nomius }\end{array}$ & Gherbawy et al., 2019 \\
\hline Serbia & $\begin{array}{l}\text { Corn, wheat, } \\
\text { barley, soybean } \\
\text { and sunflower } \\
\text { grains }\end{array}$ & A. flavus & Lević et al., 2013 \\
\hline Spain & Barley grains & $\begin{array}{l}\text { A. flavus, } A . \\
\text { parasiticus }\end{array}$ & Mateo et al., 2011 \\
\hline Tanzania & Corn grains & A. flavus & Manoza et al., 2017 \\
\hline
\end{tabular}

To eradicate or at least to decrease mycotoxins considerably in the feed and food chain is undoubtedly a high-complexity and highly prestigious aim, which absolutely requires the effective cooperation of experts working in different fields. Such expanding co-operations will hopefully help on-going research obey the "from farm to fork" principle more. In this case, this concept means that we need to deal not only with production, storage and processing issues but also their impacts on human health as well (Fink-Gremmels, 2008b; Ogunade et al., 2014; Asemoloye et al., 2017).

In this review, we focus on special parts of the feed and food chain like silage production and mitigation of mycotoxins by microbial products. A special attention will be paid to novel findings, which may help the feed management in animal husbandry to prevent and alleviate aflatoxin contamination. Other major issues tackled by this review include new pieces of information on the deleterious physiological effects of aflatoxins on domestic animals, which help us further in proper risk assessment and management. Moreover, up-to-date analytical tools and methods to measure aflatoxins precisely both on farms and analytical laboratories will also be covered. We hope that shedding light on the high-complexity relations between aflatoxin producer Aspergilli, aflatoxin contaminations in feeds and feeding practices in animal husbandry will also give us new 
<smiles>COc1cc2c(c3oc(=O)c4c(c13)CCC4=O)[C@@]1(O)C=CO[C@@H]1O2</smiles>

B1

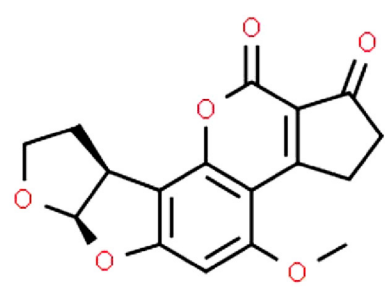

B2<smiles>COc1cc2c(c3oc(=O)c4c(c13)CCOC4=O)C1C=COC1O2</smiles>

G1

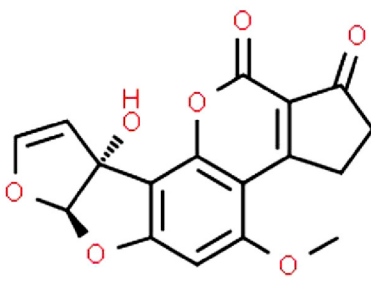

M1<smiles>COc1cc2c(c3oc(=O)c4c(c13)CCOC4=O)[C@@H]1CCO[C@H]1O2</smiles>

G2

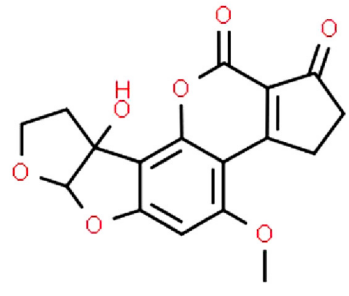

M2
FIGURE 1 | Chemical structures of aflatoxins most frequently found in animal husbandry.

hints on the efficient control of aflatoxin contaminations in feeds and minimizing the carry-over of these harmful myctotoxins to humans through the food chain.

\section{AFLATOXIN PRODUCTION IN FUNGI: BIOSYNTHESIS AND REGULATION}

Considering the aflatoxin biosynthetic pathway acetate molecules are converted to norsoloinic acid at first by two fatty acid synthases, a polyketide synthase and a monooxygenase (Ehrlich et al., 2010; Yu, 2012; Roze et al., 2013). The biosynthesis proceeds through the intermediates averantin, averufin, versiconal and branches at versicolorin $\mathrm{B}$ to give rise to aflatoxin $\mathrm{B}_{1}$ and G1 via the versicolorin A/sterigmatocystin and to aflatoxin $\mathrm{B}_{2}$ and $\mathrm{G}_{2}$ via the versicolorin $\mathrm{B} /$ dehydrosterigmatocystin pathways, respectively ( $\mathrm{Yu}, 2012$ ). The letters B and G stand for the blue and green fluorescence of these compounds observable under ultraviolet light, when separated by thin-layer chromatography (Yu, 2012). The aflatoxin biosynthetic gene cluster is sophisticatedly regulated by both local (AflR and AflS) and global (Velvet Complex) regulatory elements (Amaike and Keller, 2011; Alkhayyat and Yu, 2014; Amare and Keller, 2014; Gil-Serna et al., 2019; Keller, 2019). Environmental factors like the availability of carbon and nitrogen sources, changing $\mathrm{pH}$, temperature and light conditions as well as variations in the redox status of the fungal cells all have their impacts on aflatoxin production (Alkhayyat and Yu, 2014). Among environmental stresses, oxidative stress seems to play a pivotal role in the initiation of aflatoxin production (Reverberi et al., 2010; Hong et al., 2013; Roze et al., 2013; Amare and Keller, 2014). Plant-fungus interactions also affect the biosynthesis of aflatoxins e.g., through oxylipin production, which have been reviewed e.g., by Pusztahelyi et al. (2015). Undoubtedly, a deeper understanding of the elements and regulation of the aflatoxin biosynthetic gene clusters operating in aflatoxigenic fungi is an important prerequisite for the development of novel and successful mycotoxin control strategies in the future (Alkhayyat and Yu, 2014; Gil-Serna et al., 2019).

\section{FUNGAL ACTIVITY AND AFLATOXIN PRODUCTION IN STORED GRAINS}

Aflatoxin-producing Aspergilli (Varga et al., 2015; Chen A.J. et al., 2016; Niessen et al., 2018; Frisvad et al., 2019) may originate from crop fields but post-harvest infections have also been reported (Gachara et al., 2018). Aflatoxin production cannot be linked strictly to any specific phase of growth or processing status although poorly managed post-harvest conditions during drying and storage can result in rapid increase in mycotoxin concentrations (Hell et al., 2010; Chulze, 2010). Grain drying is costly but selecting a variety or hybrid optimal for a given crop field can help farmers to harvest cereals with lower than 13-15\% kernel moisture contents, which is required for safe storage (Magan and Aldred, 2007) (Figure 2). Nevertheless, artificial drying is unsurmountablein most cases.

Obeying quality regulations, the recommended drying temperature is less than $65^{\circ} \mathrm{C}$ for most feed cereals and below $90^{\circ} \mathrm{C}$ for corn (Hellevang, 2013). Of course, these high drying temperatures will also have on impact on the Aspergillus spp., which contaminate grains. A. flavus has an outstandingly high heat tolerance in comparison to other fungi with an upper tolerance limit of $40^{\circ} \mathrm{C}$ (Neme and Mohammed, 2017). Prencipe et al. (2018) also found that while the growth of A. flavus was suboptimal above $40^{\circ} \mathrm{C}$ this relatively high temperature resulted in the most intensive aflatoxin synthesis on chestnut. Hawkins et al. (2005) found that $60^{\circ} \mathrm{C}$ drying temperature still had no adverse effect on $A$. flavus thriving on corn kernels but raising the temperature up to $70^{\circ} \mathrm{C}$ significantly decreased fungal infection. Favorable effects of high drying temperature in the restriction of fungal growth were also reported for rice (Hell and Mutegi, 2011).

Unfortunately, the aflatoxin molecules are highly heat-stable as their decomposing temperature is $268-269^{\circ} \mathrm{C}$ (Peng et al., 2018). As a result, simple drying technologies cannot decrease aflatoxin concentrations significantly in stored grains. On the 


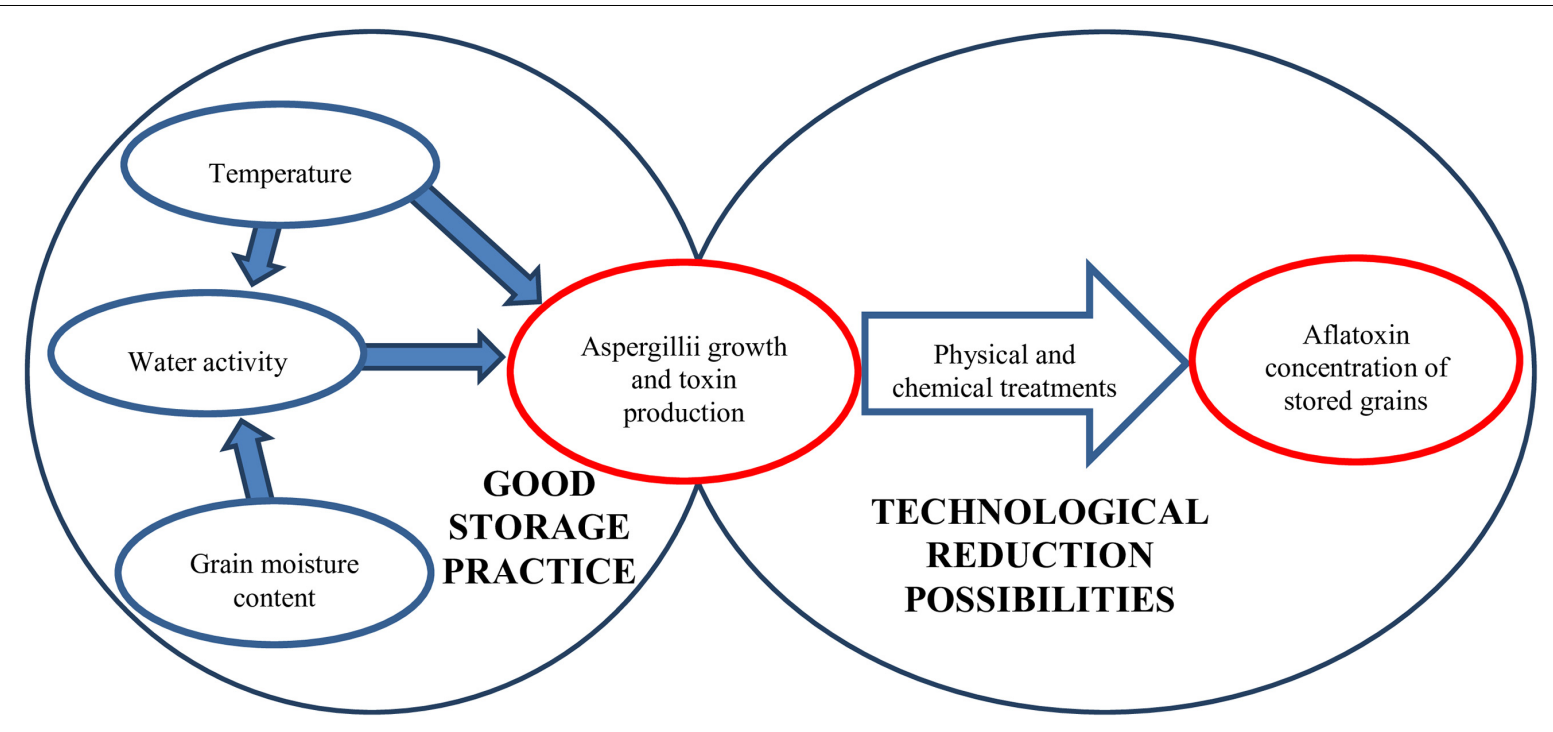

FIGURE 2 | Factors influencing the aflatoxin content of grains during storage.

other hand, elongated high-temperature treatments may have beneficial effects (Lee et al., 2015).

The temperature, kernel moisture content and relative humidity during storage all influence the physiological processes of fungi. As demonstrated, $18-19^{\circ} \mathrm{C}$ temperature and $12-13 \%$ moisture content were the limiting factors for the growth and activity of the Aspergilli (Villers, 2014; Mwakinyali et al., 2019), although lower temperature $\left(8-10^{\circ} \mathrm{C}\right)$ may also be permissive for growth and mycotoxin production when the grain moisture content is higher (Mannaa and Kim, 2017). Although these values are accepted widely in good storage practices under continental climatic conditions the relative humidity of grain silos are higher during the cold months, which results in higher water binding by the grains. Nevertheless, the lower temperature hinders increases in microbial activity, and the tolerable water activity is 0.70 for the different Aspergillus species (Mannaa and Kim, 2017). It is important to note that 'hot spots' can develop in grain heaps because of insects or increased grain physiological activity and the released heat and moisture can support fungal growth. Therefore, maintaining good hygienic practice and controlling the temperature of the grain heaps are adequate and necessary measures during storage (Magan et al., 2003; Peng et al., 2018).

There are several procedures applicable to decrease fungal infection and mycotoxin production in kernels during storage (Table 2). Size separation by sieving and density separation by gravity table are useful measures as the lighter, smaller and broken kernels and the small components of heap may be infected or damaged by fungi and, therefore, they can be starting points for further deterioration. Not surprisingly, their removal significantly decreases aflatoxin contamination (De Mello and Scussel, 2007; Shi et al., 2014; Peng et al., 2018).

Hand sorting based on visible fungal infections is a very useful tool to decrease the aflatoxin $\mathrm{B}_{1}\left(\mathrm{AFB}_{1}\right)$ content of corn kernels but obviously this is not a viable option in industrial scale (Matumba et al., 2015). Another possibility is optical sorting because $A$. flavus contaminated corn kernels emit bright greenish-yellowish light when illuminated by UV light enabling separation using suitable optical equipment. Unfortunately, such light emission does not occur in each case and hidden, internal fungi contaminations have no visible effects either. Nevertheless, a sorting method based on the evaluation of red and green light reflectance was also developed to separate aflatoxin containing peanuts and another one for cleaning pecans, based on fluorescence (Pasikatan and Dowell, 2001). It is noteworthy that a low cost multi-spectral analyzer was manufactured to screen single corn kernels at nine distinct wavelengths in the $470-1550 \mathrm{~nm}$ region for qualitative use (Stasiewicz et al., 2017). Although fluorescent optical techniques have higher sensitivities and specificities than near infrared spectroscopy-based and hyperspectral imaging methods near infrared spectroscopic evaluations seem to have greater capabilities to reveal both aflatoxin and fungal contaminations. Most importantly, these techniques have already been applied in automatic sorters (Tao et al., 2018). Color analyses can be combined easily with other visible properties. For example, the Raspberry Pi optical analytical equipment (Vasishth and Bavarva, 2016) is able to sort peanuts based on their color, size, edge length and area of kernel with more than $40 \mathrm{~kg} / \mathrm{h}$ sorting capacity. It is foreseeable that recent improvements in computing techniques will open new ways for visual analyses in combating both fungi and their mycotoxins.

Dehulling, the removal of external layers of kernel surface, can be an effective tool to decontaminate grains from toxigenic fungi and significantly decreases the aflatoxin content of grains (Siwela et al., 2005; Peng et al., 2018). This beneficial effect could be improved further by floating and washing before application (Fandohan et al., 2005; Mutungi et al., 2008; Matumba et al., 2015; Hadavi et al., 2017). Polishing rice kernels is also effective to reduce aflatoxin and, hence, more than nine-fold decrease in contamination was recorded (Castells et al., 2007). 
TABLE 2 | Summary of possibilities and examples for the reduction of the aflatoxin content of stored grains.

\begin{tabular}{|c|c|c|c|}
\hline & Method & Effect & References \\
\hline \multirow[t]{8}{*}{ Removal } & $\begin{array}{l}\text { Cleaning and sorting by } \\
\text { size and density }\end{array}$ & Only small Brazil nuts (smaller than $36.6 \mathrm{~mm}$ length and $6.3 \mathrm{~g}$ weight) contained AFB 1 & $\begin{array}{l}\text { De Mello and Scussel, } \\
2007\end{array}$ \\
\hline & & $\begin{array}{l}\text { Corn particles passed } 5.16 \mathrm{~mm} \text { sieve contained } 46 \text { times higher more toxin than the over } \\
\text { fraction and lower density kernels contain } 50 \text { times higher aflatoxin }\end{array}$ & Shi et al., 2014 \\
\hline & Sorting by color & UV light, fluorescent and multi spectral analysis can be used to detect contaminated kernels & $\begin{array}{l}\text { Pasikatan and Dowell, } \\
\text { 2001; Vasishth and } \\
\text { Bavarva, 2016; } \\
\text { Stasiewicz et al., 2017; } \\
\text { Tao et al., } 2018\end{array}$ \\
\hline & $\begin{array}{l}\text { Removal of contaminated } \\
\text { part by dehulling and } \\
\text { polishing }\end{array}$ & Dehulling removed $92 \%$ of the initial aflatoxin content from corn kernel & Siwela et al., 2005 \\
\hline & & Aflatoxin residuals in corn after crushing and dehulling was almost negligible & Fandohan et al., 2005 \\
\hline & & Dehulling decreased AF content of corn by $5.5-70 \%$ & Mutungi et al., 2008 \\
\hline & & $\begin{array}{l}\text { Dehulling and whitening of rice kernel resulted } 96 \% \text { decrease in AF content in polished } \\
\text { broken grains and } 79 \% \text { in polished whole kernels }\end{array}$ & Castells et al., 2007 \\
\hline & & Dehulling of corn kernels resulted in 88 and $92 \%$ reduction in $\mathrm{AFB}_{1}$ and $\mathrm{AFB}_{2}$ levels & Matumba et al., 2015 \\
\hline \multirow[t]{13}{*}{$\begin{array}{l}\text { Reduction, } \\
\text { destruction }\end{array}$} & $\begin{array}{l}\text { Thermal treatment for a } \\
\text { long time }\end{array}$ & $\begin{array}{l}\text { Heating at } 100 \text { and } 150^{\circ} \mathrm{C} \text { for } 90 \text { min decreased the } \mathrm{AFB}_{1} \text { content of soybean } 41.9 \text { and } \\
81.2 \% \text {, respectively }\end{array}$ & Lee et al., 2015 \\
\hline & Oxidation by ozone & $\begin{array}{l}2.8 \text { and } 5.3 \mathrm{mg} / \mathrm{l} \text { ozone concentration applied for } 4 \text { hours resulted } 76-84 \% \text { decrease in } \mathrm{AFB}_{1} \\
\text { content of poultry feed }\end{array}$ & Torlak et al., 2016 \\
\hline & & $66-95 \% \mathrm{AFB}_{1}$ reduction in peanut, corn and wheat kernel & Ismail et al., 2018 \\
\hline & $\begin{array}{l}\text { Irradiation by ionizing and } \\
\text { non-ionizing radiation }\end{array}$ & $\begin{array}{l}25 \text { kGy gamma irradiation resulted } 43 \% \text { decrease, microwave heating for } 10 \text { min at } 1.45 \mathrm{~kW} \\
\text { resulted } 32 \% \text { decrease, direct solar irradiation for } 3-30 \text { h resulted } 25-40 \% \text { decrease in } \mathrm{AFB}_{1} \\
\text { content of poultry feed }\end{array}$ & Herzallah et al., 2008 \\
\hline & & $\begin{array}{l}\text { 4, } 6 \text {, and } 8 \text { kGy gamma irradiation doses resulted } 15-56 \% \text { reduction in aflatoxin content for } \\
\text { corn, wheat and rice kernels }\end{array}$ & Mohamed et al., 2015 \\
\hline & & $\begin{array}{l}5 \text { and } 10 \text { kGy irradiation doses resulted in } 69.8 \text { and } 94.5 \% \text { decreases in } \text { AFB }_{1} \text { content, } \\
\text { respectively }\end{array}$ & Markov et al., 2015 \\
\hline & & $\begin{array}{l}\text { Pulsed light treatment }\left(0.52 \mathrm{~J} / \mathrm{cm}^{2} / \text { pulse in spectrum of } 100-1100 \mathrm{~nm} \text { with a xenon flash }\right. \\
\text { lamp) resulted } 75-90 \% \text { decreases in } \mathrm{AFB}_{1} \text { and } \mathrm{AFB}_{2} \text { contents of rice and rice bran }\end{array}$ & Wang et al., 2016 \\
\hline & & 6 and 10 kGy gamma irradiation doses resulted 90 and $95 \%$ reduction in $\mathrm{AFB}_{1}$, respectively & Serra et al., 2018 \\
\hline & & $\begin{array}{l}\text { In peanuts, } 5-9 \text { kGy gamma irradiation doses result } 20-43 \% \text { decrease in aflatoxins, } \\
\text { microwave radiation at } 360,480 \text {, and } 600 \mathrm{~W} \text { resulted } 59-67 \% \text { decrease, combined } \\
\text { treatments have higher than } 95 \% \text { efficiency }\end{array}$ & Patil et al., 2019 \\
\hline & Destruction by cold plasma & $\begin{array}{l}\text { Hazelnuts, peanuts, and pistachio nuts treated with air gases plasma for } 20 \text { min resulted } 50 \% \\
\text { decrease in total aflatoxins, } \mathrm{SF}_{6} \text { plasma application resulted only } 20 \% \text { reduction }\end{array}$ & Basaran et al., 2008 \\
\hline & & $\begin{array}{l}\text { Atmospheric plasma generated with } 400-1150 \mathrm{~W} \text { power for } 1-12 \text { min resulted } 46-71 \% \\
\text { decrease in } \mathrm{AFB}_{1} \text { in peanuts }\end{array}$ & Siciliano et al., 2016 \\
\hline & & $\begin{array}{l}\text { High voltage atmospheric cold plasma applied for } 1 \text { and } 10 \text { min resulted } 62 \text { and } 82 \% \\
\text { reduction in AFs levels of corn. }\end{array}$ & Shi et al., 2017 \\
\hline & & Atmospheric and low pressure cold plasma reduced the AFB ${ }_{1}$ content of hazelnut by $72-73 \%$ & Sen et al., 2019 \\
\hline
\end{tabular}

Application of ozone during cereal storage is a relatively new method to improve storage conditions, based on the combined antifungal and insecticide effects of this reactive gas (Isikber and Athanassiou, 2015). Importantly, ozone treatments reduce mycotoxin contaminants without any negative effect on the quality of the grains (Tiwari et al., 2010; Zhu, 2018), and eliminate aflatoxins with high efficiency (66-95\% of the original toxin concentration) in cereal grains and flours, as well as in soybean and peanut (Torlak et al., 2016; Ismail et al., 2018).

Another physical method to reduce aflatoxin contaminations is irradiation. Several radiation sources have been evaluated thus far and many of them were found to be effective. For example, the advantageous effects of UV in liquid phase (Patras et al., 2017), gamma irradiation in corn (Markov et al., 2015; Serra et al., 2018), in other cereal kernels (Mohamed et al., 2015), in peanuts (Patil et al., 2019) and in poultry feed (Herzallah et al., 2008) have been reported in a number of publications. Direct sunlight was also effective in aflatoxin reduction in poultry feed (Herzallah et al., 2008) and, in addition to exposures to direct light, the applicability of pulsed light has also been tested and evaluated, and it has already been employed in new decontamination technologies (Moreau et al., 2013). Meanwhile exposure to pulsed light was effective in liquid medium (Moreau et al., 2013) pulsed polychromatic light applied with a simple xenon flash lamp also resulted in significant decreases in the aflatoxin content in cereal kernels (Wang et al., 2016). 
Cold plasma treatment is another possible physical treatment against pathogens and fungal toxins. Cold plasma is generally a result of atmospheric dielectric discharge, and the effects of pressure (atmospheric or vacuum), air composition, humidity and flow rate, discharging power and treatment time are under continuous evaluation nowadays in different cereals and nuts (Basaran et al., 2008; Siciliano et al., 2016; Shi et al., 2017; Misra et al., 2019; Sen et al., 2019). Cold plasma treatments are cost effective, ecologically neutral and have only a negligible effect on the quality of the grains when compared to classical detoxification methods (Hojnik et al., 2017).

\section{FUNGAL ACTIVITY AND AFLATOXIN PRODUCTION IN SILAGE}

Climate change has a major impact on agriculture in many ways and, thereby, many studies have already been published on the effects of climate change on the growth, spread and toxin production of mycotoxigenic fungi on economically important crops (Magan et al., 2011; Paterson and Lima, 2011; Wu et al., 2011; Battilani et al., 2012, 2016).

Aflatoxin contaminations of maize, wheat, etc. have become a major safety issue in the European agricultural industry (Battilani et al., 2016), and aflatoxin producer Aspergillus spp. have also been detected in temperate Europe (Dobolyi et al., 2013). As a consequence, mycotoxins including the Aspergillusderived harmful aflatoxins may also contaminate European agricultural products - a foreseeable threat, which we should by no means neglect (Magan et al., 2011; Battilani et al., 2012, 2016; Dobolyi et al., 2013).

Maize silage, one of the most important components in the feeding of dairy cows in Europe and worldwide, can be contaminated by several mycotoxin-producer fungi entering the feed production chain at various stages (Ogunade et al., 2018). Not surprisingly, aflatoxin contaminations can be detected occasionally both before and after ensiling (Storm et al., 2014; Gallo et al., 2015; Ogunade et al., 2018; Peng et al., 2018). Therefore, the rigorous control of the growth of aflatoxigenic fungi is of pivotal importance, if the production of aflatoxinfree silage is to be guaranteed (Borreani and Tabacco, 2010; Ogunade et al., 2018).
Although microaerophilic conditions and low $\mathrm{pH}$, which are typical features of silage fermentations, may prevent the growth of the majority of molds, some species of the genera Aspergillus, Byssochlamys, Monascus, Penicillium, and Trichoderma are able to survive even under ensiling conditions (Mansfield and Kuldau, 2007; Pereyra et al., 2008). To make things even worse, the aflatoxigenic capacity of the Aspergillus section Flavi strains derived from silage samples is remarkable. For example, del Palacio et al. (2016) demonstrated that $27.5 \%$ of these strains produced $\mathrm{AFB}_{1}, 17.5 \%$ of them aflatoxin $\mathrm{G}_{2}\left(\mathrm{AFG}_{2}\right)$ and $10 \%$ synthesized aflatoxin $\mathrm{G}_{1}\left(\mathrm{AFG}_{1}\right)$. Interestingly, only $5 \%$ of the strains produced $\mathrm{AFB}_{2}$ (del Palacio et al., 2016). In another study concomitantly performed in Pakistan (Sultana et al., 2017), A. niger, A. flavus, A. fumigatus, A. ochraceous, and A. terrus were identified in both fresh fodder and corn silage. Importantly, the authors also found $\mathrm{AFB}_{1}$ in $37.5 \%$ of the fresh fodder and in $41.7 \%$ of the corn silage samples with average $\mathrm{AFB}_{1}$ concentrations of 9.5 and $8.4 \mu \mathrm{g} / \mathrm{kg}$, respectively, meanwhile $\mathrm{AFB}_{2}$ was present in only two samples (1.2 and $1.3 \mu \mathrm{g} / \mathrm{kg}$ ), and none of the analyzed samples was contaminated by $\mathrm{AFG}_{1}$ or $\mathrm{AFG}_{2}$ (Sultana et al., 2017). In Southern Brazil, aflatoxigenic A. parasiticus and A. nomius strains have been detected in the tested silage and concentrated feed samples (Variane et al., 2018).

Considering the world-wide occurrence of aflatoxin contaminations (Table 3 ), $\mathrm{AFB}_{1}$ has been reported in corn silage in Argentina (González Pereyra et al., 2008, 2011), in Brazil (Keller et al., 2013; Schmidt et al., 2015), and in France (Richard et al., 2009). Total aflatoxin contaminations have also been determined in silage samples collected in Iran (Hashemi et al., 2012) and in Uruguay (del Palacio et al., 2016).

\section{MICROBIAL BIOCONTROL AND MICROBIAL DETOXIFICATION PRODUCTS FOR MYCOTOXIN MITIGATION IN ANIMAL HUSBANDRY}

In recent decades, several feasible and cost-effective strategies have entered the market aiming to mitigate the effects of feed mycotoxin contamination in animal husbandry, especially in the dairy industry. Technologies to reduce the incidence

TABLE 3 | Worldwide occurrence of aflatoxins in silage.

\begin{tabular}{|c|c|c|c|c|c|c|c|}
\hline Country & Mycotoxin & Sample & $\begin{array}{l}\text { No. of } \\
\text { samples }\end{array}$ & $\begin{array}{c}\text { No. of positive } \\
\text { sample (Incidence\%) }\end{array}$ & $\begin{array}{l}\text { Mean concentration } \\
(\mu \mathrm{g} / \mathrm{kg})\end{array}$ & $\begin{array}{l}\text { Range } \\
(\mu \mathrm{g} / \mathrm{kg})\end{array}$ & References \\
\hline Argentina & $\mathrm{AFB}_{1}$ & Corn silage & 35 & $6(17.0 \%)$ & - & $1.4-155.8$ & González Pereyra et al., 2008 \\
\hline Argentina & $\mathrm{AFB}_{1}$ & Trench silo & 43 & $6(14.0 \%)$ & - & $1.0-190.0$ & González Pereyra et al., 2011 \\
\hline Argentina & $\mathrm{AFB}_{1}$ & Silo bag & 35 & $19(54.3 \%)$ & - & $5.8-47.4$ & González Pereyra et al., 2011 \\
\hline Brazil & $\mathrm{AFB}_{1}$ & Corn silage & 116 & $15(13.0 \%)$ & 33.0 & $2.0-61.0$ & Keller et al., 2013 \\
\hline Brazil & $\mathrm{AFB}_{1}$ & Corn silage & 327 & $3(0.9 \%)$ & 3.0 & $1.0-6.0$ & Schmidt et al., 2015 \\
\hline France & $\mathrm{AFB}_{1}$ & Corn silage & - & - & 28.0 & $7.0-51.3$ & Richard et al., 2009 \\
\hline Iran & Total AF & Silage & 42 & $7(16.7 \%)$ & 1.24 & $1.1-27.3$ & Hashemi et al., 2012 \\
\hline Uruguay & Total AF & Wheat silage & 220 & - & 17.0 & $6.1-23.3$ & del Palacio et al., 2016 \\
\hline
\end{tabular}

-, not evaluated data. 
of mold and mycotoxin contaminations of silages can be employed in one of the three main phases (preharvest, harvest, ensiling) of silage production. During the preharvest phase, the appropriate agronomic practices may rely on (i) the use of crop varieties or hybrids, which are resistant to fungal infections, (ii) the application of pesticides and fungicides, (iii) adequate management of weeds and crop residues, (iv) the use of appropriate crop rotation, tillage, fertilization and irrigation and (v) the application of biocontrol agents, e.g., bacteria, yeasts, or atoxigenic strains of $A$. flavus or A. parasiticus (Gallo et al., 2015; Pfliegler et al., 2015; Ogunade et al., 2018; Peng et al., 2018). During the harvest phase, the most important factors that should be taken into consideration are proper harvest timing (maturity stage) and cutting height (to minimize soil contamination), as well as immediate storage of harvested feeds (Gallo et al., 2015; Ogunade et al., 2018; Peng et al., 2018).

Pre-harvest biocontrol microbes represent a promising and already widely applied method to lower mycotoxin risks in food and feed by protecting plants from pathogens and inhibiting the growth of molds during postharvest conditions. They both reduce economic loss caused by fungal infections and lower toxin levels in products (e.g., Pfliegler et al., 2015). Biocontrol agents compete for nutrients and space, may secrete antifungals or even parasitize molds, and can also stimulate host plant resistance (Liu et al., 2013) and, thereby, they mitigate the risk of plant infections and their undesirable consequences. Regarding Aspergilli infection and aflatoxin contamination, non-aflatoxigenic biocontrol Aspergillus flavus strains are most commonly applied to crops (Ehrlich, 2014; Weaver and Abbas, 2019), while biocontrol yeasts species are also effective, such as the 2-phenylethanol producing Wickerhamomyces anomalus (Hua et al., 2014). These biocontrol agents are mostly applied to protect plants directly used in food production but may exert their effects on plant parts that are to be ensiled for feed production concomitantly.

In the ensiling phase, attention must be payed to adequate particle size, proper silo size, immediate rapid filling, proper compaction, complete sealing (to maintain strictly anaerobic conditions), and the use of acid-based additives or microbial inoculants, e.g., lactic acid bacteria (Gallo et al., 2015; Ogunade et al., 2018; Peng et al., 2018). Some specific strains in the Lactobacillus (L. buchneri, L. fermentum, L. hilgardii, L. plantarum, L. reuteri, L. rhamnosus), Lactococcus (L. lactis), Leuconostoc, and Pediococcus (P. pentosaceus) genera can inhibit or can even prevent completely the growths of various mycotoxigenic molds and their mycotoxin productions as well (Dalié et al., 2010; Cavallarin et al., 2011; Queiroz et al., 2012; Dogi et al., 2013; Ahlberg et al., 2015; Ma et al., 2017; Gallo et al., 2018; Zielińska and Fabiszewska, 2018; Ferrero et al., 2019). It is noteworthy that there is a wide spectrum of environmental factors which influence the antifungal activity of LAB, including the type of the matrix and culture medium, the availability of nutritional compounds, the incubation time and temperature (Dalié et al., 2010; Ahlberg et al., 2015; Leyva Salas et al., 2017). In addition, some biological (e.g., the natural microbiota), and chemical (e.g., $\mathrm{pH}$, water activity) parameters will also affect the antifungal activity in a species-specific manner
(Dalié et al., 2010; Ahlberg et al., 2015; Leyva Salas et al., 2017). Species- and strain-specific factors are noteworthy, for example both $L$. rhamnosus and L. plantarum were efficient against $A$. parasiticus only L. rhamnosus reduced the AFB1 levels produced by A. parasiticus (Dogi et al., 2013). Quite unexpectedly, the A. parasiticus - L. plantarum interaction even stimulated aflatoxin $B_{1}$ production, which makes the use of L. plantarum undesirable as a silage inoculant.

In another study, a mixture of $P$. pentosaceus and L. buchneri reduced the adverse effects of rust infestation during ensiling and also decreased aerobic spoilage and aflatoxin production in maize silages with high levels of southern rust infestation (Queiroz et al., 2012). Importantly, L. buchneri increased the aerobic stability of the silage as well (Cavallarin et al., 2011). Inoculation of corn silage with a combined inoculant of L. buchneri and Lactococcus lactis improved the aerobic stability of the silage, and the higher silage density increased the stability further (Gallo et al., 2018). The interaction of L. buchneri, L. reuteri, L. plantarum, and L. fermentum strains reduced the $\mathrm{AFB}_{1}$ level, improved the stability and, furthermore, the microbiological and chemical purity of maize silage (Zielińska and Fabiszewska, 2018). In a most recent study by Ferrero et al. (2019), the authors examined the effect of L. buchneri, Lactobacillus hilgardii, and their combination on A. flavus contaminants and their aflatoxin production in maize silage. The results showed that the inoculation of corn silage with L. buchneri and L. hilgardii increased the aerobic stability and delayed the beginning of aerobic microbial degradation of maize silage, and indirectly reduced the risk of $A$. flavus emergence and aflatoxin $B_{1}$ level after silage opening.

Ma et al. (2017) examined the $\mathrm{AFB}_{1}$ binding capacity of various silage bacteria including L. plantarum, L. buchneri, $P$. acidilactici, and $P$. pentosaceus and found that high concentration of silage bacteria could bind the $\mathrm{AFB}_{1}$ content of maize silage but population, strain, viability, and medium acidity have all affected the efficacy of binding.

Antifungal compounds produced by LAB also reduce the mycotoxin production of molds (Ahlberg et al., 2015). These LAB-produced compounds cover organic acids (e.g., acetic, lactic, and propionic acid), carboxylic acids, phenolic compounds, including phenolic acids (gallic acid, tannins, benzoic acids, phenyllactic acid, hydroxyphenyllactic acid), fatty acids (caproic acid, decanoic acid, 3-hydroxydecanoic acid, coriolic acid, ricinoleic acid), volatile compounds (e.g., diacetyl, acetoin), cyclopeptides [e.g., cyclo(Phe-Pro), cyclo(L-Leu-L-Pro), cyclo(L-Met-L-Pro), cyclo(L-Tyr-L-Pro)], hydrogen peroxide, ethanol, reuterin, and proteinaceous compounds (Dalié et al., 2010; Li et al., 2012; Crowley et al., 2013; Le Lay et al., 2016; Leyva Salas et al., 2017).

Considering the mechanisms of actions of these antifungals, the dissociated forms of organic acids can decrease the intracellular $\mathrm{pH}$ within the cells, can increase the permeability of the cytoplasmic membrane, and finally can lead to the death of the fungal cells (Leyva Salas et al., 2017). In addition, $\mathrm{H}_{2} \mathrm{O}_{2}$ oxidizes directly the cellular proteins and the lipid components of the cellular membranes (Dalié et al., 2010). Nevertheless, the mechanisms of the antifungal actions of hydroxy fatty acids and 
TABLE 4 | Antifungal activity of lactic acid bacteria (LAB).

\begin{tabular}{|c|c|c|c|}
\hline LAB & Strain & Effect & References \\
\hline Lactobacillus buchneri & NCIMB 40788 & $\begin{array}{l}\text { Decreased mold count, decreased } \mathrm{AFB}_{2} \text { and increased aerobic stability of } \\
\text { the silage }\end{array}$ & Cavallarin et al., 2011 \\
\hline Lb. buchneri & 40788 & Decreased the population of spoilage fungi, and aflatoxin production in silages & Queiroz et al., 2012 \\
\hline Lb. buchneri & $\mathrm{R} 1102$ & Bound $\mathrm{AFB}_{1}$ & Ma et al., 2017 \\
\hline Lb. buchneri & LB1819 & Enhanced the fermentation and aerobic stability of maize silage & Gallo et al., 2018 \\
\hline Lb. buchneri & A KKP 2047 p & Reduced mold count and decreased $\mathrm{AFB}_{1}$ amount & Zielińska and Fabiszewska, 2018 \\
\hline Lb. buchneri & NCIMB 40788 & $\begin{array}{l}\text { Reduced the risk of Aspergillus flavus outgrowth and } \text { AFB }_{1} \text { production after } \\
\text { silage opening }\end{array}$ & Ferrero et al., 2019 \\
\hline Lactobacillus fermentum & N KKP 2020 p & Reduced mold count and decreased AFB $_{1}$ amount & Zielińska and Fabiszewska, 2018 \\
\hline Lactobacillus hilgardii & CNCM I-4785 & $\begin{array}{l}\text { Reduced the risk of Aspergillus flavus outgrowth and } \text { AFB }_{1} \text { production after } \\
\text { silage opening }\end{array}$ & Ferrero et al., 2019 \\
\hline Lactobacillus plantarum & RC009 & Reduce Aspergillus parasiticus growth rate & Dogi et al., 2013 \\
\hline Lb. plantarum & PT5B & Bound $\mathrm{AFB}_{1}$ & Ma et al., 2017 \\
\hline Lb. plantarum & $\begin{array}{l}\text { K KKP } 593 \text { p, } \\
\text { S KKP } 2021 \text { p }\end{array}$ & Reduced mold count and decreased AFB $_{1}$ amount & Zielińska and Fabiszewska, 2018 \\
\hline Lactobacillus reuteri & M KKP 2048 p & Reduced mold count and decreased AFB 1 amount & Zielińska and Fabiszewska, 2018 \\
\hline Lactobacillus rhamnosus & RC007 & Reduce Aspergillus parasiticus growth rate & Dogi et al., 2013 \\
\hline Lactococcus lactis & $\mathrm{O} 224$ & Enhanced the fermentation and aerobic stability of maize silage & Gallo et al., 2018 \\
\hline Pediococcus pentosaceus & 12455 & Decreased the population of spoilage fungi and aflatoxin production in silages & Queiroz et al., 2012 \\
\hline Pediococcus acidilactici & R2142, EQ01 & Bound $\mathrm{AFB}_{1}$ & Ma et al., 2017 \\
\hline
\end{tabular}

proteinaceous compounds have remained yet to be elucidated (Dalié et al., 2010).

Silage decontamination may also be applied if measures to avoid contamination were proven ineffective. Such strategies are primarily based on the adsorbents. Advantages of using adsorbent feed additives over decontamination of the final product, e.g., milk, are their safety and inexpensiveness, and that they may simply be mixed into animal feed to achieve the desired effect. These products may lower the bioavailability of mycotoxins and can help to decrease toxic effects, as well as the amount of toxin detectable in the final product (meat or milk). Such strategies may involve the use of live microbial (LAB or yeast) cultures (usually termed microbial enterosorption, biosorption), microbial or plant extracts, other organic/inorganic materials such as activated carbons or charcoals, hydrated sodium calcium aluminosilicates, and various clay-based products (Kutz et al., 2009; Giovati et al., 2015). LAB can not only inhibit the growth of molds but are also able to bind aflatoxins in different matrices (Table 4; Ahlberg et al., 2015; Muck et al., 2018), thereby reducing the health risks of aflatoxins. Environmental conditions have a great impact on the aflatoxin binding capabilities of LAB (Dalié et al., 2010; Ahlberg et al., 2015; Ma et al., 2017), which is highly species-specific (Gomah et al., 2010; Dogi et al., 2013; Ahlberg et al., 2015). Some studies demonstrated that nonviable $\mathrm{LAB}$ cells had better binding capability for aflatoxin than viable LAB cells (Ahlberg et al., 2015; Damayanti et al., 2017; Ma et al., 2017). On the contrary, Liew et al. (2018) reported on a higher binding efficiency by living cells. Regardless of alive or dead bacterial cells, the aflatoxin binding seems to be reversible and the bound mycotoxins are released slowly over time (Verheecke et al., 2016).

Based on various microbe species, sources, manufacturers, and formulations, live yeast products include several categories: yeast probiotics, Saccharomyces cerevisiae fermentation products (SCFP), dried yeast products (DY or DYP), brewery yeasts (BY), and active dry S. cerevisiae (ADSC) (Pizzolitto et al., 2012; Poppy et al., 2012; Gonçalves et al., 2017). Compared to live bacteria-based products, these yeast products are considered and employed as direct feed additives in most cases and are not applied at the ensiling phase (Giovati et al., 2015). Some bacterial species, e.g., Nocardia corynebacteroides (NC) are also added as direct feed additives for poultry (Tejada-Castañeda et al., 2008). Microbe-derived feed additive products are also based on yeasts, and include autolyzed yeast (AZ), inactivated yeast cells (IY), distillery yeast sludge, and yeast cell wall (YCW) products (Gonçalves et al., 2017; Plaizier et al., 2018).

Live yeast or bacterial cells intended to colonize the gastrointestinal tract (GIT) of humans, or in some cases, poultry or laboratory rodents, are occasionally termed probiotics (Śliżewska and Smulikowska, 2011; Pizzolitto et al., 2012; González Pereyra et al., 2014). However, especially in the case of ruminants, the use of live cells may not necessarily result in gastrointestinal colonization. The rumen's own microbiota is also to be taken into account, as it can contribute to aflatoxin detoxification and degradation (e.g., biotransformation to aflatoxicol) (Upadhaya et al., 2009; Jiang et al., 2012). Aflatoxin $\mathrm{B} 1$ is absorbed in the rumen mainly at acidic pH (Pantaya et al., 2014), and the degradation of aflatoxins in rumen depends on both the animal species and feed type (Upadhaya et al., 2009). However, it must be noted that rumen colonization by A. flavus has also been recorded, leading to toxin production in rumen liquor (Nidhina et al., 2017).

The products SCFP, DY, BY, and ADSC consist of yeast cells, the nutrient medium on which the yeasts were grown, and the metabolites produced by the yeasts and have been shown to increase DMI, milk yield, as well as milk fat and protein yield in 


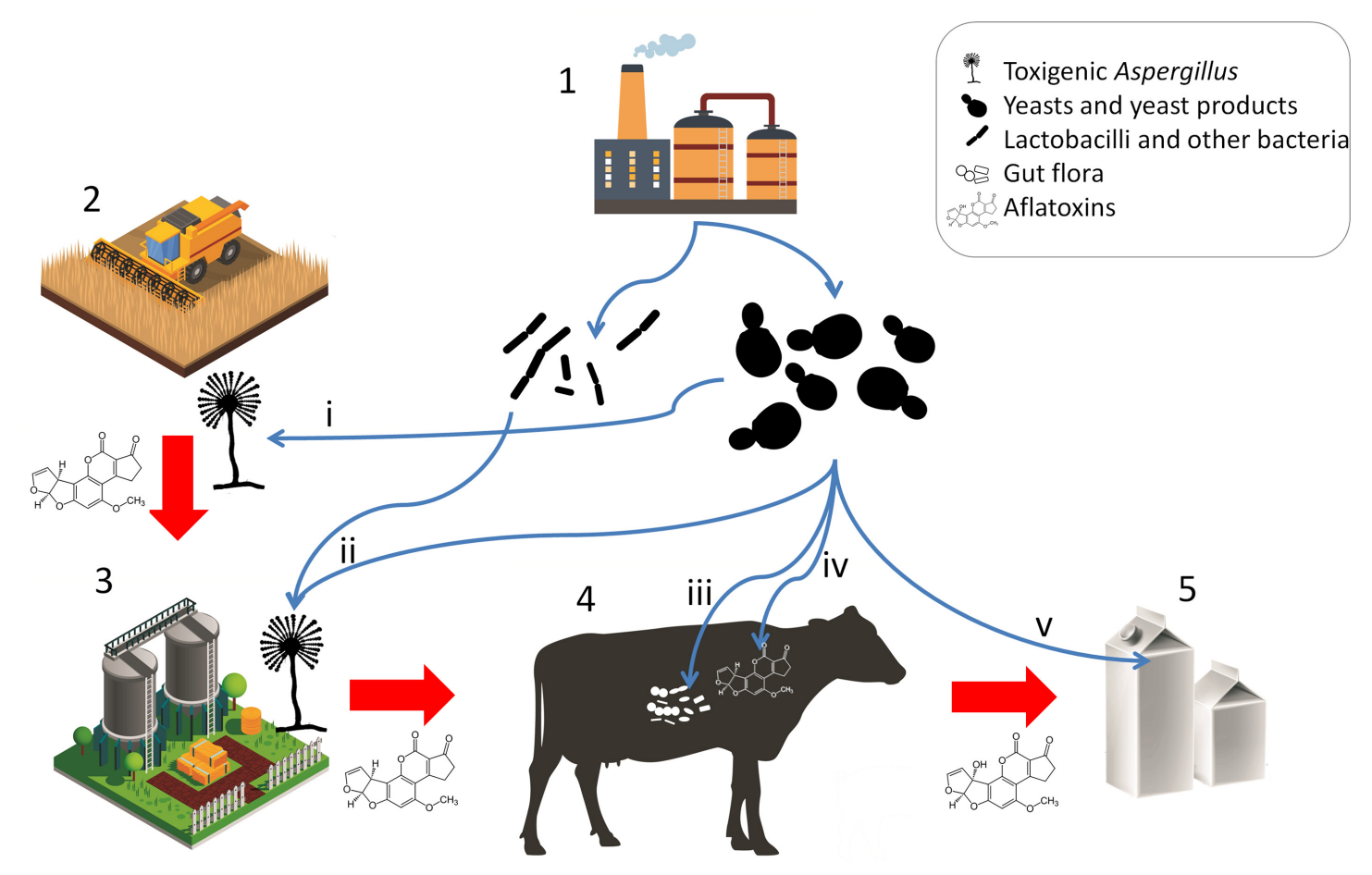

FIGURE 3 | Microbial products for mycotoxin mitigation in animal husbandry and their applications. Red arrows represent potential carry-over of mycotoxins or toxigenic Aspergilli. Blue arrows represent applications of microbes and microbe-derived products. (1) Fermentation and animal feed supplement industries; (2) crop production; (3) preparation and storage of silage and other feedstuffs; (4) livestock; (5) product; (i) pre-harvest biocontrol; (ii) antagonism in silage and feed; (iii) host gut microbiota and immune modulation, probiotic effect; (iv) enterosorption; (v) bioadsorption from product (milk). [Stock image credits: Freepik, macrovector, and vectorpocket].

lactating dairy cows (Poppy et al., 2012). However, these positive effects are attributed to adsorption of toxic substances and the modulation of the gut (prokaryote) microbiota, not to long-term gut colonization by the yeasts. Yeasts in fact are thought to play a negligible role in the microbiome of ruminants, although they may survive gastrointestinal conditions and retain their aflatoxin $\mathrm{B}_{1}$ binding ability under gastrointestinal conditions (Dogi et al., 2011). Various studies have shown the effects of these live yeast products on the microbiota of the cows, however, uncovering the underlying mechanisms and a holistic understanding of dairy cow gastrointestinal health still requires further research (Zhu et al., 2017; Huebner et al., 2019). Interestingly, YCW has also been shown to positively modulate the gut health in broiler chicken challenged with $\mathrm{AFB}_{1}$ or with Clostridium infection (Liu et al., 2018). These observations raise the possibility that yeast products, whether live or not, generally contribute to animal health both as bioadsorbents and as modulators of the gut prokaryote microbiota, as well as the immune status of the animal. Such positive effects may not only prevent toxicosis but result in increased feed intake and production (Pasha, 2008). In poultry feedstuff, $S$. cerevisiae strains have been tested and made commercially available as a probiotic microbe. It must be noted though, that the intended effect of the yeasts is not necessarily gut colonization and microbiome modulation, but aflatoxin adsorption (Śliżewska and Smulikowska, 2011;
Pizzolitto et al., 2012), a role, which yeasts can effectively fulfill. The applications of microbes and microbial products for mycotoxin risk mitigation are summarized in Figure 3.

Yeast cell wall $\beta$-D-glucans, glucomannans and mannanoligosaccharides are responsible for the mycotoxin binding abilities of these products (Pfliegler et al., 2015). Some purified cell wall components have been tested in animal husbandry, such as mannan-oligosaccharides supplemented into the diet of Japanese quails affected by aflatoxicoses (Oguz and Parlat, 2005). However, no direct correlation between the amount of individual components and toxin binding are evident (JoannisCassan et al., 2011). Structural integrity and amount of the yeast cell wall is crucial in binding efficacy, while viability is not: heat-treatment can even increase adsorption capacity (Bueno et al., 2007; Joannis-Cassan et al., 2011). Toxin binding can reach saturation rapidly and is reversible, and mycotoxins are not modified chemically during the process (Bueno et al., 2007). It must be noted that some yeasts (reviewed by Pfliegler et al., 2015) and bacteria (Wang Y. et al., 2018) are known to be able to enzymatically degrade mycotoxins if applied in viable form.

A novel approach for the microbiological detoxification of animal feed is the screening of isolates from various environmental sources (Intanoo et al., 2018), instead of using the most widespread species, S. cerevisiae. Various bacteria and yeasts may exhibit toxin-binding or even toxin-degrading 
abilities, as well as biocontrol effects on toxigenic molds (Pfliegler et al., 2015) and these may be directly applied to supplement animal feed (Intanoo et al., 2018). Novel yeast species in this field include members of the genera Kluyveromyces and Pichia, both related to the widely used Saccharomyces. $P$. kudriavzevii has been successfully applied as a bioadsorbent feed additive to ameliorate the negative effects of $\mathrm{AFB}_{1}$ contamination on broiler chicken performance (Magnoli et al., 2017). Novel isolates of $K$. marxianus have also been proposed as bioadsorbents based on in vitro characterization (Intanoo et al., 2018). However, Battacone et al. (2009) found no evidence for $\mathrm{AFB}_{1}$ detoxification in ewes fed with Kluyveromyces lactis DYP, highlighting the need for rigorous testing of novel strains in different setups and with multiple animal species.

Apart from novel microbial strains, combined treatments of microbial and inorganic products constitute a promising strategy in ameliorating mycotoxin contamination. Recently, Jiang et al. (2018) found that both dietary clay and clay + SCFP reduced transfer of dietary $\mathrm{AFB}_{1}$ to milk as well as milk aflatoxin $\mathrm{M}_{1}$ $\left(\mathrm{AFM}_{1}\right)$ concentration, while the combined treatment was the only one that also prevented the decrease in milk yield caused by $\mathrm{AFB}_{1}$. Thus, the potent adsorbing capability of inorganic products may act synergistically with the adsorbent, gut healthpromoting and immunomodulatory effects of yeast products.

\section{MICROBIAL DETOXIFICATION PRODUCTS TO COUNTERACT AFLATOXIN CONTAMINATION IN DAIRY PRODUCTS}

Some studies have explored microbial aflatoxin decontamination strategies in dairy products, taking advantage of the high efficacy and relative ease of utilizing $\mathrm{LAB}$ and yeast, recently been reviewed by Assaf et al. (2019). Briefly, such microbial decontamination approaches rely on heat-killed or immobilized cells, and promising results were obtained when both LAB and yeasts were applied simultaneously. Heat-treatment of bacterial cells was found to improve binding capabilities in some studies (Pierides et al., 2000; Bovo et al., 2015; Assaf et al., 2018), while no such effect was reported by Kabak and Var (2008). Bacteria tested in the aforementioned studies include members of the genera traditionally considered probiotics and/or important in food production, as Bifidobacterium, Lactobacillus, or Pediococcus, and oddly, a potential pathogen, Enterococcus.

In UHT skim milk, both LAB and yeasts showed promising results (Corassin et al., 2013), and the binding of toxins to microbial cell walls was shown to be rapid, enabling short incubation times in potential industrial applications. Yeasts of the genera Saccharomyces and Kluyveromyces have been tested by Abdelmotilib et al. (2018), where the higher efficacy of heat-killed cells was also demonstrated for yeasts.

There are certain limitations on applying yeasts and bacteria for the decontamination of dairy products (Assaf et al., 2019), such as the need for their subsequent removal, reversibility of binding, or even legislations on tolerated number of live or dead microbial cells in products. Nevertheless, the high toxin binding capability and the safety of heat-killed cells toward consumers compared to chemical methods makes microbial decontamination a promising strategy.

\section{AFLATOXIN METABOLISM IN LIVESTOCK}

The toxicity of $\mathrm{AFB}_{1}$ is strictly related to the bioactivation and detoxification pathways operating animals in vivo (Figure 4). Indeed, $\mathrm{AFB}_{1}$ is a "pro-carcinogen" that is activated biologically by cytochrome P450 (CYP450), a microsomal enzyme of phase I detoxification (oxidation) to the extremely reactive and electrophilic $\mathrm{AFB}_{1}-8,9$-epoxide (AFBO). This harmful $\mathrm{AFB}_{1}$ derivative is able to covalently bind to macromolecules such as DNA and proteins, thereby forming adducts, which cause acute and chronic cytotoxicity, DNA mutations and eventually expressing carcinogenic activity (Diaz et al., 2010; Deng et al., 2018).

Moreover, $\mathrm{AFBO}$ can be hydrolyzed to $\mathrm{AFB}_{1}$-8,9-dihydrodiol $\left(\mathrm{AFB}_{1}\right.$-dhd) by an epoxide hydrolase. $\mathrm{AFB}_{1}$-dhd is able to react with proteins causing cytotoxicity or, alternatively, AFBO can be metabolically detoxified via conjugation with glutathione (GSH) by glutathione S-transferase (GST), a phase II detoxification enzyme. This pathway is considered as one of the main routes of AFBO detoxification (Diaz et al., 2010; Deng et al., 2018). Microsomal epoxide hydrolase $(\mathrm{mEH})$ and aflatoxin-aldehyde reductase $(A F A R)$ can also transform reactive $A F B_{1}$ to $A_{F B}$ dialcohol, a real detoxified $\mathrm{AFB}_{1}$ derivative, which can be excreted in urine (Guengerich et al., 2001; Deng et al., 2018).

It is important to note that several isoenzymes belonging to the CYP450 supergene family metabolize $\mathrm{AFB}_{1}$ through oxidative reactions, producing various metabolites with different carcinogenic potential.

In addition to the highly reactive and toxic AFBO, the main $\mathrm{AFB}_{1}$ metabolic pathways described in animals can also give rise to relatively less toxic metabolites such as aflatoxicol (AFL) by ketoreduction or $\mathrm{AFM}_{1}$ by hydroxylation and nontoxic metabolites such as $\mathrm{AFB}_{2}$ a or aflatoxin $\mathrm{Q}_{1}\left(\mathrm{AFQ}_{1}\right)$ by hydroxylation or aflatoxic $\mathrm{P}_{1}\left(\mathrm{AFP}_{1}\right)$ by demethylation (Figure 4; Dohnal et al., 2014; Deng et al., 2018).

Current literature data indicate that the rates of the bioactivation and detoxification of $\mathrm{AFB}_{1}$ contribute greatly to the manifestation of its toxic effects. Furthermore, the metabolism of aflatoxins shows considerable interspatial differences and also significant variations among individuals belonging to the same species, depending for example on the age (Dohnal et al., 2014).

In conclusion, the largely different sensitivities of different animal species to the toxic effects of aflatoxins could be explained mainly with the remarkable variability of the metabolic pathways and enzymes that contribute to the bioactivation and detoxification of aflatoxins (Dohnal et al., 2014).

\section{Poultry}

Poultry are generally very sensitive to $\mathrm{AFB}_{1}$ and adverse health effects have been reported in turkeys, quail, chickens, and ducks 


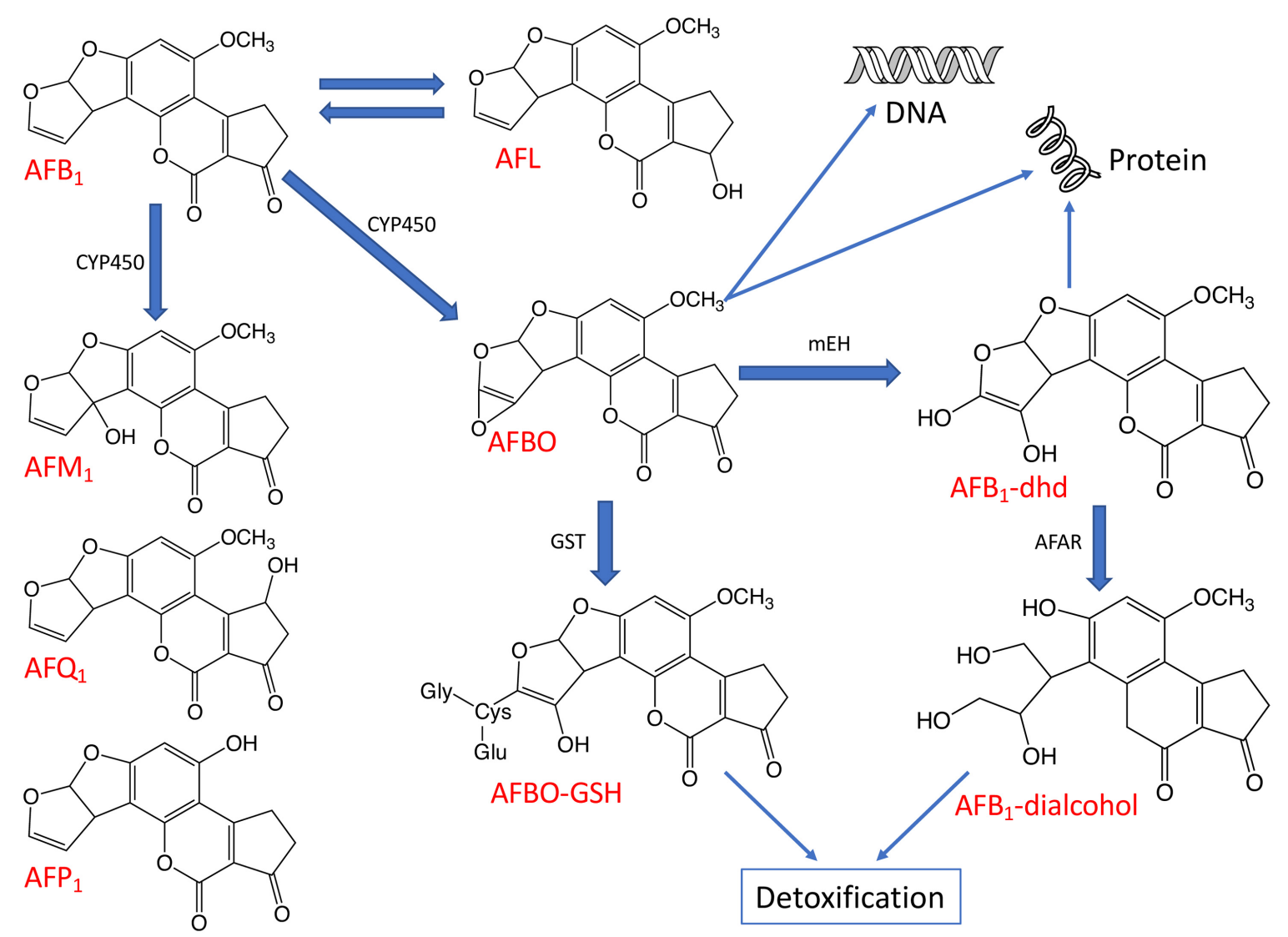

FIGURE 4 | The major metabolic pathways of $A F B_{1}$. The aflatoxin derivatives presented here include aflatoxin $B_{1}\left(A F B_{1}\right)$, aflatoxin $M_{1}\left(A F M_{1}\right)$, aflatoxin $Q_{1}\left(A F Q_{1}\right)$, aflatoxin $\mathrm{P}_{1}\left(\mathrm{AFP}_{1}\right), \mathrm{AFB}_{1}$-8,9-epoxide (AFBO), AFB 1 -8,9-dihydrodiol (AFB 1 -dhd) and aflatoxicol (AFL). Some enzymes taking part in the biotransformation and detoxification of aflatoxins are also indicated including cytochrome P450 (CYP450), glutathione-S-transferase (GST), microsomal epoxide hydrolase (mEH), and aflatoxin-aldehyde reductase (AFAR).

but there is a great variability in species-specific sensitivities to aflatoxins (Klein et al., 2000; Diaz et al., 2010; Rawal et al., 2010). Several toxicological studies pointed at the existence of a sensitivity scale starting from the less resistant young duck and turkey, followed by quails, up to the more resistant chickens. Obviously, species-specific differences in the $\mathrm{AFB}_{1}$ biotransformation pathways, e.g., in $\mathrm{AFB}_{1}$ modifying hepatic microsomal enzymes, could explain the varying susceptibilities of the species (Lozano and Diaz, 2006). It has been reported in some works that the microsomal liver fractions produced only AFBO in avian species (Figure 4), unless these animals were stimulated with CYP450 inducers (Lozano and Diaz, 2006). However, the ability of poultry species to metabolize $\mathrm{AFB}_{1}$ to $\mathrm{AFM}_{1}$ was reported in other works, in which the $\mathrm{AFM}_{1}$ was detected in different tissues (Madden and Stahr, 1995; Wang H. et al., 2018). Lozano and Diaz (2006) reported that turkey microsomes produced 1.8-3.5 times more AFBO than quail and chicken microsomes. Furthermore, Diaz et al. (2010) suggested that the higher resistance of chicken to $\mathrm{AFB}_{1}$ in comparison to quail could be due to a lower activation rate of $\mathrm{AFB}_{1}$ to $\mathrm{AFBO}$ in chicken and also to a lower affinity for $\mathrm{AFB}_{1}$ of the chicken microsomal enzymes.
The high susceptibility of poultry to $\mathrm{AFB}_{1}$ appears to be a consequence of both the high activity of phase I microsomal detoxification enzymes to form AFBO, and to a low GST efficiency as well to conjugate AFBO with GSH (phase II detoxification). Some works reported that the partial or complete lack of GST-dependent detoxification of AFBO was the major reason for the exceptionally high susceptibility of poultry including turkeys to $\mathrm{AFB}_{1}$ (Klein et al., 2000; Rawal et al., 2010).

Another metabolic pathway that may contribute to the extreme susceptibility of poultry to aflatoxins could be the reduction of $\mathrm{AFB}_{1}$ to $\mathrm{AFL}$ via cytosolic reductase because the cytosolic metabolite AFL is produced in larger quantities in turkey and duck than in quail and chicken. This fact underlines that the formation of AFL cannot be regarded as a real detoxification pathway in these birds, moreover, microsomal dehydrogenase may oxidize AFL back to $\mathrm{AFB}_{1}$, increasing the physiological half life of $\mathrm{AFB}_{1}$ (Lozano and Diaz, 2006). Other aflatoxin metabolic pathways may also be involved in the manifestation of the high cytotoxicity of $\mathrm{AFB}_{1}$ in poultry species.

Furthermore, it has also been reported that $\mathrm{AFB}_{1}$ susceptibility correlated with age in both turkeys and broiler chickens. When livers obtained from 9, 45, and 61 day-old turkeys 
were compared, microsomes from younger birds were more active in $\mathrm{AFB}_{1}$ bioactivation than those from older ones (Klein et al., 2002). Moreover, Wang H. et al. (2018) underlined the efficient bioactivation of $\mathrm{AFB}_{1}$ by CYP enzymes and the deficient detoxification by GST enzymes in younger 7-day old broilers.

Aflatoxin residues were detected in various tissues mainly in liver, kidney, the organs where $\mathrm{AFB}_{1}$ is metabolized, but also in reproductive organs, in gizzard, breast and in legs (Herzallah et al., 2014). The metabolites $\mathrm{AFB}_{1}, \mathrm{AFQ}_{1}$, and AFL were excreted as such or as glucuronyl conjugates from bile in feces (Yunus et al., 2011). Some of these metabolites (AFM 1 and AFL) have been found in liver, kidneys and thigh muscles (Micco et al., 1988). The concentrations of $\mathrm{AFB}_{1}$ residues decreased in the livers and muscles of all the birds after the suspension of mycotoxin feeding, and the elimination of $\mathrm{AFB}_{1}$ from tissues was faster in older than in younger birds (Yunus et al., 2011). The dietary exposure to aflatoxin of hens, even at low concentrations, may also cause contamination of eggs. $\mathrm{AFB}_{1}$ residues appeared in eggs after 5 days following the administration of $\mathrm{AFB}_{1}$ contaminated feedstuffs, and they accumulated in line with protracted feeding with contaminated grain (Hassan et al., 2012). However, the amount of mycotoxin contaminants was below $0.1 \%$ of the $\mathrm{AFB}_{1}$ intake owing to the $\mathrm{AFB}_{1}$ metabolism in the birds. Few works also demonstrated the presence of hydroxylated $\mathrm{AFB}_{1}$ derivatives $\left(\mathrm{AFM}_{1}\right.$ and $\left.\mathrm{AFQ}_{1}\right)$ in eggs (Anfossi et al., 2015).

\section{Pigs}

Pigs are considered relatively susceptible to $\mathrm{AFB}_{1}$. Tulayakul et al. (2006) studied $\mathrm{AFB}_{1}$ metabolism in liver of different species in relation to the susceptibility to the toxic effects. The piglet's liver showed a relatively lower cytosolic GST activity to convert $\mathrm{AFB}_{1}$ epoxide to $\mathrm{AFB}_{1}$-glutathione conjugate product, thus favoring the formation of $\mathrm{AFB}_{1}$-DNA adducts.

The metabolism and tissue distribution of $\mathrm{AFB}_{1}$ in pigs were studied by Lüthy et al. (1980), and the major excretory route was found to be the feces (51-65\% of the dose administered) but also urine was also an important excretory route. Actually, both $\mathrm{AFM}_{1}$ and $\mathrm{AFB}_{1}$ were detected in pig urine samples and $\mathrm{AFM}_{1}$ was always found at higher concentrations in all studies (Thieu and Pettersson, 2009). In fact, urinary $\mathrm{AFB}_{1}$ and $\mathrm{AFM}_{1}$ are often used as biomarkers for aflatoxin exposure in pigs.

\section{Ruminants}

Ruminants are generally more resistant to the toxic effects of mycotoxins than monogastric animals, which could be explained mainly by $\mathrm{AFB}_{1}$ degradation or bioconversion by rumen microorganisms. Controversely, some studies reported on that aflatoxins were generally poorly bioconverted in the rumen, with an overall decrease of only $10 \%$ (Westlake et al., 1989). Moreover, $\mathrm{AFB}_{1}$ was incubated with intact rumen fluid or fractions of rumen protozoa and bacteria from sheep and cattle in the presence or absence of milled feed and the result clearly indicated that rumen fluid had no effect on $\mathrm{AFB}_{1}$ (Kiessling et al., 1984). Another study showed that $\mathrm{AFB}_{1}$ metabolism in rumen fluid was influenced by the animal species and the type of feed. In fact, rumen microbes from Korean native goats exhibited a greater degradation capacity for $\mathrm{AFB}_{1}$ in comparison to Holstein steers. These diverging observations might be the consequence of varying rumen microbe profiles (Upadhaya et al., 2009).

$\mathrm{AFM}_{1}$ is the most prominent metabolite formed in bovine hepatocytes within the first hours of incubation whereas $\mathrm{AFB}_{1}$ dhd becomes determinative after a prolonged incubation. These two metabolites are mainly formed by CYP1A and CYP3A hepatic monooxygenase activities (Kuilman et al., 2000). According to Larsson et al. (1994), several extrahepatic tissues of sheep can also bioactivate $\mathrm{AFB}_{1}$ very efficiently and can conjugate the bioactivated $\mathrm{AFB}_{1}$ with $\mathrm{GSH}$ as well.

Following the channeling of $\mathrm{AFB}_{1}$ in ruminants, the ingested aflatoxins may be degraded, at least in part, to AFL, $\mathrm{AFM}_{1}$ and many other hydroxylated metabolites by certain rumen microbes or may be sequestered by some rumen fluid components such as chlorophyllin structures as well as bacterial and yeast cell walls (Gallo et al., 2015). The remaining fraction is rapidly adsorbed in the gastro-intestinal tract by passive diffusion and then is extensively metabolized in the liver to $\mathrm{AFM}_{1}$, which enters the systemic circulation or is conjugated to glucuronic acid, and afterward excreted via bile, urine or milk (Kuilman et al., 2000; Rodrigues et al., 2019). Obviously, different levels of feed contamination may lead to different carry-over rates, which are also influenced by other physiological factors such the health status of animals including the status of the liver and its enzymatic activities. $\mathrm{AFB}_{1}, \mathrm{AFM}_{1}$ and AFL have been detected in liver, kidney and muscle tissue of bovine (Kuilman et al., 1998). $\mathrm{AFM}_{1}$ is excreted via urine at a greater extent than through milk but the physiological factors regulating the relative uptake by kidneys and mammary glands are still unknown (Rodrigues et al., 2019). $\mathrm{AFM}_{1}$ has been detected in both the milk and urine of cattle and dairy ewes $6 \mathrm{~h}$ after $\mathrm{AFB}_{1}$ ingestion (Helferich et al., 1986; Battacone et al., 2003), and its concentration decreased rapidly after withdrawal of aflatoxin from diets (Rodrigues et al., 2019). Fecal excretion of $\mathrm{FB}_{1}$ results from a lack of absorption by the GIT or a highly efficient elimination by the biliary system in the form of conjugated metabolites (Yiannikouris and Jouany, 2002; Jouany et al., 2009).

Goats were administrated with $\left[{ }^{14} \mathrm{C}\right]-\mathrm{AFB}_{1}$, and urine, milk and feces were collected after $120 \mathrm{~h}$. $\mathrm{AFM}_{1}$ was found in milk at the highest concentration meanwhile $\mathrm{AFQ}_{1}$ and AFL were found only in trace quantities in milk (Helferich et al., 1986). Other studies on goats also indicated that the absorption of $\mathrm{AFB}_{1}$ in the GIT of adult ruminants was very fast, as was its hydroxylation to $\mathrm{AFM}_{1}$ and release into the blood (Battacone et al., 2012). The short interval between $\mathrm{AFB}_{1}$ administration and the detection of its metabolite in milk confirmed that the absorption of the toxin took place already in the rumen in goats.

\section{AFLATOXINS IN FOODS OF ANIMAL ORIGIN}

Aflatoxins are generally considered as the most important mycotoxins due to their carcinogenic properties, their persistence in food commodities once formed, and the wide range of food commodities that may be contaminated by them (FinkGremmels and van der Merwe, 2019). Aflatoxins contaminating 
feeds pose a direct threat to livestock health and, indirectly, also affect human nutrition and health by reducing livestock productivity and via transfer from feed to foods of animal origin, namely milk, meat and eggs, even if milk is the only food of animal origin with relevant aflatoxin carry-over (Frazzoli et al., 2017).

Aflatoxins, particularly $\mathrm{AFM}_{1}$, are of public health concern because they are efficiently excreted into milk, even if they may also contaminate other foods of animal origin at low levels and, therefore, the associated risks are considered to be minor (FinkGremmels and van der Merwe, 2019). Not surprisingly, many countries have set maximum levels of aflatoxins $\left(\mathrm{AFB}_{1}\right.$ or total aflatoxins, $\mathrm{AFM}_{1}$ ) in food commodities and animal feeds, with the main aims to protect animal health and to prevent aflatoxin contamination of animal-derived foods. This review does not provide a systematic overview on aflatoxins in foods of animal origin but summarizes the discussions on the potential public health concerns specifically related to aflatoxins residues in these food commodities. In livestock animals, the best estimate transfer factors for mycotoxins in kidney, liver, muscle, fat, milk and egg were reported by MacLachlan (2011), and they clearly showed that no significant residues coming from aflatoxin contaminants of livestock feed are present in meat and eggs.

In the case of human dietary exposure from dairy products, aflatoxins are considered the most important mycotoxins and, based on data belonging to Food and Feed Safety Alert, 93\% of the overall mycotoxin notifications referred to aflatoxins, whereas dioxins, dioxin-like polychlorinated biphenyls and $\mathrm{AFM}_{1}$ were the most frequently reported chemical issues in dairy products (van Asselt et al., 2017). When ruminants were fed with contaminated feed, the $\mathrm{AFB}_{1}$ consumed by the animals was partly degraded by the forestomach before reaching the circulatory system, and the remaining part was transformed by the liver into monohydroxy derivative forms, mainly to $\mathrm{AFM}_{1}$, and, in smaller quantities, also to $\mathrm{AFM}_{2}, \mathrm{AFM}_{4}$ and AFL. Afterward, $\mathrm{AFM}_{1}$ was secreted into the milk through the mammary glands (Frazzoli et al., 2017). $\mathrm{AFM}_{1}$ has only from 2 to $10 \%$ of the carcinogenic potency of $\mathrm{AFB}_{1}$ but it possesses the same liver toxicity. The ability of ruminants to convert the $\mathrm{AFB}_{1}$ ingested with feedstuff to $\mathrm{AFM}_{1}$ and to excrete this derivative in milk varies within broad limits in large and small ruminants and ranges between 0.35 and $3 \%$ in cows, 0.018 and $3.1 \%$ in goats and between 0.08 and $0.33 \%$ in sheep (Virdis et al., 2014). This remarkable variability in $\mathrm{AFB}_{1}$ biotransformation observed in these species can be explained with differences in the activity of hepatic enzymes involved in the biotransformation and detoxification processes considering both their expression and catalytic activity (Becker-Algeri et al., 2016). The average conversion value was $2.5 \%$ (Veldman et al., 1992) in high yielding dairy cows, which produced a daily amount of about $40 \mathrm{~L}$ of milk, were tested. Importantly, Veldman et al. (1992) found a direct relationship between the carry-over rate and the milk yield with a maximal $6.2 \%$ carryover rate. $\mathrm{AFM}_{1}$ is the most commonly detected aflatoxin in milk and the excretion of $\mathrm{AFM}_{1}$ depends on a range of factors including diet composition, rumen degradation and liver biotransformation capacities, the duration of lactation (Fink-Gremmels and van der Merwe, 2019) as well as on the animal breed and udder health status (Masoero et al., 2007). In dairy cows ingesting $\mathrm{AFB}_{1}$ contaminated feedstuffs, the excretoin of $\mathrm{AFM}_{1}$ occured in 12 $24 \mathrm{~h}$ and up to $2-3$ days in milk, whereas the $\mathrm{AFM}_{1}$ clearance in milk depended on several factors, mainly on the amount of ingested $\mathrm{AFB}_{1}$ and the duration of mycotoxin consumption with an excretion for a variable period of about $5-7$ days from the ending of $\mathrm{AFB}_{1}$ assumption by cows (Masoero et al., 2007).

Well-reported variations in $\mathrm{AFM}_{1}$ contamination were observed in milk worldwide, which were dependent on several factors like geographical area, environmental and climatic conditions including seasons and weather, as well as on the diversity and level of development of farming systems and the consumption of feed concentrates and green forage (BeckerAlgeri et al., 2016). In recent years and independently of the type of commodity, the occurrence of $\mathrm{AFM}_{1}$ in milk and dairy products was lower in Europe (for example in Italy, Portugal, Turkia, and Croatia) than in Asia or South America, where higher mycotoxin frequencies up to $100 \%$ were reported (Filazi and Sireli, 2013; Becker-Algeri et al., 2016). In Europe, low levels of $\mathrm{AFM}_{1}$ contamination were reported in milk, and only $0.06 \%$ of the analyzed samples were above the European limit of $0.05 \mu \mathrm{g} / \mathrm{kg}$ milk. Nevertheless, when such incidents occur a widespread $\mathrm{AFM}_{1}$ contamination of milk may develop, which has to be taken into account and adequately considered and controlled (van Asselt et al., 2017). In addition, risk managers should also consider that aflatoxin concentrations in milk may vary within the year and may also depend on the geographical location and climatic conditions. Finally, $\mathrm{AFM}_{2}$ has also been investigated in milk with different outcomes varying from its absence to a not negligible occurrence in powdered, UHT and pasteurized milk samples (Becker-Algeri et al., 2016).

The $\mathrm{AFM}_{1}$ contamination of dairy products is classified as an indirect contamination. For example, when the milk used in cheese-making was contaminated by aflatoxins, $\mathrm{AFM}_{1}$ unevenly distributes between whey and curd, because $\mathrm{AFM}_{1}$ prefers to bind to milk proteins, first of all to casein. For this reason, $\mathrm{AFM}_{1}$ is more concentrated in the curd and cheese than in the milk itself, which was used for cheese-making (Anfossi et al., 2012). Therefore, $\mathrm{AFM}_{1}$ levels were 3 - 8 times higher in certain dairy products than in the milk, and stable $\mathrm{AFM}_{1}$ residues were detected in the final dairy products like milk powder even after heat processing. In addition, the total amount of $\mathrm{AFM}_{1}$ does not change significantly during the cheese-making and cheese maturation processes but these steps influence the $\mathrm{AFM}_{1}$ and protein concentration ratios as a result of skimming and water loss (Anfossi et al., 2012). Although many studies on the contaminations of dairy products by $\mathrm{AFM}_{1}$ are available (Anfossi et al., 2012; Becker-Algeri et al., 2016) only few of them present any data estimating concentration factors for $\mathrm{AFM}_{1}$ in different cheeses. However, 2.5 - 3.3 and $3.9-5.8$ times higher concentrations of $\mathrm{AFM}_{1}$ calculated on a weight basis were recorded in soft and hard cheeses, respectively, than those $\mathrm{AFM}_{1}$ concentrations found in the milk, from which these cheeses were made (Filazi and Sireli, 2013). In Europe, the food business operator has to justify and provide the specific concentration or dilution factors for $\mathrm{AFM}_{1}$ in the processed 
foodstuffs during official controls performed by the competent authority (EC Regulation, 1881/2016).

In this context, $\mathrm{AFM}_{1}$ contaminating milk should be unremitting to our attention and we should also take a special care of infants avoiding their exposures to $\mathrm{AFM}_{1}$ via milk and infant formulas (Fink-Gremmels and van der Merwe, 2019). Kerekes et al. (2016) emphasized the importance of regular control of produced milk and also the introduction of an appropriate action limit in combination with immediate corrective actions at the farm level. In fact, feed producers have to manage and control the feed ingredients intended for the production of feed for the lactating animals for risk mitigation. Feed ingredients should be selected based on their quality characteristics, whereas farmers, when the $\mathrm{AFM}_{1}$ content of milk exceeds the legal limit, have to withdraw milk consignments and also have to remove contaminated feedstuffs (Trevisani et al., 2014).

As far as the aflatoxin residues detected in edible tissues of bovine, pigs and poultry are concerned, these $\mathrm{AFB}_{1}$ entry routes do not contribute significantly to human aflatoxin exposures (Fink-Gremmels and van der Merwe, 2019). Nevertheless, data on the aflatoxin contents in the edible tissues of bovine species are scarce and it is generally assumed that aflatoxins are partly degraded in the rumen and they are rapidly metabolized in the liver after absorption from the intestines. The transfer rates of aflatoxins into the edible tissues of pigs are very low owing to the rapid pre-systemic and hepatic metabolisms, and the aflatoxin residues in pork are therefore not considered as of public health concern. Similarly, poultry with low levels of aflatoxin contaminations do not seem hazardous to humans although the presence of aflatoxin-residues in poultry liver is well-documented (Fink-Gremmels and van der Merwe, 2019). Importantly, a rapid decrease in $\mathrm{AFB}_{1}$ residues was observed in poultry muscles and liver after 3-7 days of uncontaminated dietary, significantly reducing the risk for human health (Filazi and Sireli, 2013). However, AFL is the main component of total AF residues in poultry with highest contents in liver (Frazzoli et al., 2017). In the case of laying hens, aflatoxins and their metabolites, particularly $\mathrm{AFB}_{1}$ itself and $\mathrm{AFL}$, can also be carried over to eggs but very discrepant transmission ratios were reported in this case. Recent studies demonstrated very low amounts of aflatoxin residues in eggs, merely between 0.01\% (Herzallah, 2013 ) and $0.07 \%$ (Hassan et al., 2012) of the aflatoxin intake. $\mathrm{AFB}_{1}$ residues appeared in eggs after 5 days of feeding with contaminated feedstuffs and the amount of $\mathrm{AFB}_{1}$ depended on the duration of feeding with contaminated grain. Similar to dairy products, the presence of aflatoxins in eggs may be indicative of the aflatoxins contamination of the feed.

\section{AFLATOXICOSES AND ANIMAL SUSCEPTIBILITY}

In general, mycotoxicosis refers to syndromes appearing after ingestion, skin contact or inhalation of toxic secondary metabolites produced by toxigenic molds belonging to the genera Aspergillus, Fusarium, and Penicillium as well as to some other fungal taxa (Gallo et al., 2015). Within mycotoxicoses, aflatoxicosis refers to any disease caused by the consumption of foods and feeds contaminated with aflatoxins. It is well-known that $\mathrm{AFB}_{1}$ is a potent mutagenic, carcinogenic, teratogenic, and immunosuppressive fungal secondary metabolite and all these effects may be linked to the interference of $\mathrm{AFB}_{1}$ and its derivatives with the synthesis of proteins, the inhibition of various metabolic pathways or to the onset of oxidative stress. All these disadvantageous physiological effects will lead consequently to damages in various organs, especially in the liver, kidney, and the heart.

Aflatoxicoses may emerge in any livestock but literature reports on outbreaks mostly in poultry, pigs, equine, sheep, and cattle. The exposure of domestic animals to $\mathrm{AFB}_{1}$ mainly occurs through the ingestion of contaminated feeds, however, skin contacts or inhalation exposures might also contribute (Gallo et al., 2015). It is well-known that ruminants are among the least susceptible animals to the negative effects of mycotoxins in comparison to monogastrics. However, the rumen has a saturable capacity of detoxifying aflatoxins by microflora, depending on (i) variations in the diet, (ii) the consequences of metabolic diseases, such as rumen acidosis, (iii) rumen barrier alterations as a result of animal diseases, and also (iv) the actual concentrations of aflatoxins present in the animal feed (FinkGremmels, 2008a). Consequently, clinical manifestations of aflatoxicoses in ruminants are associated typically with aflatoxins that are not degraded at all or not completely degraded by the rumen microflora.

Most of the data we have already had in our hands on mycotoxin toxicity are coming from experimental studies with purified compounds in otherwise healthy animals, which knowledge may help us with the early and reliable diagnosis of mycotoxicoses. However, when natural episodes of mycotoxicoses occur, versatile signs of disease could appear depending on the environmental conditions and also on several other features of the animals involved, including nutrition, sex and breed. For this reason, the diagnosis of mycotoxicoses is often difficult but it should rely on observing the clinical symptoms on the affected animals and also on analyzing the feed involved in the intoxication (Council for Agricultural Science and Technology [CAST], 2003). Given aflatoxins could act in synergy with other mycotoxins and also with other disease-provoking agents and, therefore, additional apparently unrelated pathological symptoms and even diseases are observed and reported in the affected animals. Furthermore, most mycotoxicoses including aflatoxicoses may present non-pathognomonic features and, consequently, there are no definitive diagnostic symptoms to orient farmers and veterinarians to assign aflatoxin exposures unequivocally to the death of animals. Obviously, even other otherwise unrelated diseases may trigger similar responses in the domestic animals to those of aflatoxins (Richard, 2008).

Aflatoxins do not affect all animals uniformly. Some animal species are inherently more resistant, such as sheep, goats and cattle, whereas other animals are more susceptible like swine, chickens, turkeys, and ducklings. In addition, considerable breed differences are documented within a given species (Richard, 2008), and the physiological responses to the adverse effects of 
aflatoxins are also influenced by age (young animals are usually more sensitive than elder ones and, in particular, piglets and chicks), sex, diet, and weight, exposure to infectious agents, and the presence of other mycotoxins or other pharmacologically active substances (Zain, 2011). In addition, when mycotoxins are present simultaneously, some interactive effects, classified as additive, antagonistic or synergistic, could also occur (Gallo et al., 2015).

\section{Animal Exposure to Aflatoxins}

The exposure of animals to aflatoxins may trigger biological reactions that could be classified as acute, overt diseases with high morbidity and mortality, or, as it is usually the case, chronic, insidious disorders that impairs animal productivity (Bryden, 2012; Pierron et al., 2016). When livestock ingest aflatoxins the health effects could be acute, with severe consequences and evident signs of disease or even may be lethal when these toxins are abundantly consumed, even if this event is rare under farm conditions (Gallo et al., 2015). The timing of the proper diagnosis is a crucially important factor because the suspicious contaminated feed is likely consumed well before it can be tested (Council for Agricultural Science and Technology [CAST], 2003). The earliest clinical signs and lesions observed in turkey " $X$ " disease, hepatitis " $X$ " of dogs, and similar cases of acute aflatoxicoses were anorexia, lethargy, hemorrhages, hepatic necrosis, and bile duct proliferation (Miller and Wilson, 1994). Furthermore, the aflatoxins' impact on animals should not be limited to the extreme effects of aflatoxicoses because it is related mainly to the chronic toxicity caused by the consumption of sublethal doses and to the fact that low levels of chronic exposures may result in cancer.

Considering the chronic effects of aflatoxins, hidden pathological alterations with reduced ingestion, productivity and fertility were implied, including lowered milk, meat, and egg productions, decreased weight gains and/or unclear changes in animal growth, feed intake reductions or feed refusals, alterations in nutrient absorption and metabolism, various typologies of damages to vital body organs, disadvantageous effects on the reproduction and endocrine systems and also suppression of the immune system with subsequently increased disease incidence. The economic consequences of chronic aflatoxicoses are many times larger than those of the rare acute cases with immediate morbidity and lethality (Council for Agricultural Science and Technology [CAST], 2003).

\section{Hepatotoxic, Carcinogenic and Mutagenic Effects}

Among the major devastating effects of aflatoxins on animals, these harmful metabolites specifically target the liver and, hence, are proved to be primarily hepatotoxic. In acute aflatoxicosis, the emerging clinical symptoms of acute hepatic injury include coagulopathy, increased capillary fragility, hemorrhage and prolonged clotting times. Gross liver changes are caused by hemorrhage, centrilobular congestion, and fatty changes in surviving hepatocytes. Death of the poisoned animal may occur within hours or a few days after exposure. In broiler chicks, hemorrhagic anemia syndrome develops as characterized by massive hemorrhagic lesions in major organs and musculature even if the anemia could be considered as a secondary effect of severe hypoproteinemia caused by primary liver damage (Council for Agricultural Science and Technology [CAST], 2003). However, changes in extrinsic coagulation factors as determined by increased fibrinogen concentration were also reported in lambs (Zain, 2011). In addition, in broiler chicks, other reported clinical signs of aflatoxicosis were glomerular hypertrophy, hydropic degeneration of tubuler epithelium in kidneys and increases in the number of mesengial cells, as well as atrophy and lymphoid depletion in the thymus and bursa of Fabricius (Ortatatli and Oguz, 2001).

Even in chronic aflatoxicosis, most of the effects can be attributed to hepatic injury but with milder symptomes and icterus can also be observed. The pathological alterations in the liver mostly consist of degenerative changes and circulatory disturbances and also include a yellow to brassy color, enlarged gall bladder, diluted bile, histological signs of fatty changes in the hepatocytes, bile duct proliferation and periportal necrosis. In chronic aflatoxicosis, the signs are so protean that the episode may go undiagnosed for long periods of time (Pier, 1992). Because aflatoxins metabolized in the liver, the histological changes are observed primarily within this organ. Not surprisingly, centrilobular hepatic necrosis or hepatocellular vacuolar change and bile duct proliferation are consistent lesions in cow, sheep, goat and swine. Hepatic fibrosis has been reported in all species when the animals did not die from acute aflatoxicosis (Miller and Wilson, 1994). In Piedmontese calves, an outbreak of hepatic encephalopathy consequent to aflatoxin intoxication is to be mentioned: neurological signs varying from comatose or depressed mental status, spinal hyporeflexia, wasting and proprioceptive deficits, and compulsive behavior characterized by anteropulsion and right circling in large circles (D’Angelo et al., 2007).

Aflatoxins are also carcinogenic in animals and aflatoxin $B_{1}$ is the most powerful liver carcinogen known for rats. $\mathrm{AFB}_{1}$ and $\mathrm{AFG}_{1}$ possess an unsaturated bond at the 8,9 position on the terminal furan ring (Figures 1, 4), and epoxidation at this position results in a reactive species, which induces oxidative stress of tissues, depletes antioxidants, forms DNA adducts and, hence, initiates malignant transformations. $\mathrm{AFB}_{2}$ and $\mathrm{AFG}_{2}$ are relatively less toxic unless they are metabolically oxidized first to $\mathrm{AFB}_{1}$ and $\mathrm{AFG}_{1}$ in vivo. Chronic exposure to low doses of aflatoxins is one of the major risk factors in the etiology of hepatocellular carcinoma, and all animal models exposed to $\mathrm{AFB}_{1}$ have developed this type of cancerous desease thus far. Aflatoxins have been reported to cause other malignancies as well, including adenomas of esophagus, trachea, kidney and lungs, carcinoma of the pancreas and osteogenic sarcomas (Yilmaz et al., 2018). However, the carcinogenicity in farmed animals cannot be detected because of the relatively short period of time, in which the animals are fed prior to marketing (Richard, 2008). In addition, the chronic form of aflatoxicosis includes teratogenic effects in animals, which are associated with congenital malformations and, in the fetuses, multiple skeletal anomalies as incomplete ossification of skull 
bones and failure of ossification of long and flat bones, as well as delay in the intramembranous ossification process, defects in the vertebrae formation or their reduction in size. Other mutagenic effects of aflatoxins cover mutations in genes, alterations of DNA by chromosomal breaks, rearrangement of chromosome pieces or even acquisition or loss of entire chromosomes (Fetaih et al., 2014).

\section{Immunotoxic Effects}

Although aflatoxins are primarily known as hepatotoxins and hepatocarcinogens, they have notable immunotoxic effects as well making animals more susceptible to many bacterial, viral, fungal and parasitic infections, as well as to the reactivation of chronic infections or reductions in vaccine and therapeutic efficacies (Oswald et al., 2005). Poultry (chickens and turkeys), pigs and in particular lambs are susceptible to induced immunosuppression due to aflatoxin exposure. Aflatoxins could impair both the cellular and humoral immune systems. In vitro and in vivo studies have demonstrated that $\mathrm{AFB}_{1}$ is immunotoxic, exerting its action particularly on cell-mediated immunity through (i) reducing the number of circulating lymphocytes, (ii) the inhibition or suppression of lymphocyte blastogenesis, (iii) impairing both cutaneous delayed-type hypersensitivity and graft versus host reaction and (iv) the modification of the activities of natural killer cells and of macrophage functions through the inhibition of phagocytosis, the expression and secretion of cytokines (TNF- $\alpha$, IL-1 $\beta$, IL-6, IL-10, and IFN- $\gamma$ ), and also by reducing intracellular killing as well as the spontaneous production of oxidative radicals (Council for Agricultural Science and Technology [CAST], 2003; Oswald et al., 2005; Meissonnier et al., 2008). The general mechanism of the immunosuppressive effects of $\mathrm{AFB}_{1}$ appears to be directly associated with the impairment of the synthesis of proteins. In fact, $\mathrm{AFB}_{1}$ is transformed in vivo into metabolites, which are able to bind actively DNA and RNA, to impair the activity of DNA-dependent RNA polymerase and also to inhibit the synthesis of both RNA and proteins. These inhibitory mechanisms have direct and indirect effects on the proliferation and differentiation of the lymphoid system cells and on the synthesis of cytokines involved in the regulation of the immune system (Oswald et al., 2005). An alteration of the inflammatory responses with a reduced synthesis of pro-inflammatory cytokines and an increase of anti-inflammatory cytokines was reported in weanling piglets fed for 4 weeks with low doses of aflatoxin (Marin et al., 2002). The effects of aflatoxins on humoral immunity are not so clear as their effects on cell-mediated immunity, and these differences are hardly recognizable between the different animal species unless higher doses of aflatoxins were introduced (Council for Agricultural Science and Technology [CAST], 2003; Meissonnier et al., 2008). Suppression of humoral immunity has also been recorded after observing decreases in lymphocyte infiltration, hemagglutination and in serum protein levels (Rushing and Selim, 2019). In pig, no major effects on humoral immunity were observed after $\mathrm{AFB}_{1}$ exposure but delayed and decreased ovalbumin-specific proliferation, suggesting an impaired lymphocyte activation (Pierron et al., 2016). However, a biphasic effect of $\mathrm{AFB}_{1}$ was shown in piglets and broiler chicks, with immunosuppressive effects observable during acute exposures and with inflammatory response with stimulatory effects depending on the doses, more precisely, low doses of $\mathrm{AFB}_{1}$ caused immunosuppression meanwhile high doses of it stimulated the immune system (Marin et al., 2002; Yunus et al., 2011). In details, piglets showed decreased leukocyte counts when exposed to low $\mathrm{AFB}_{1}$, and an increase in leukocytes with a high dose (Marin et al., 2002). This immunotoxic effect has significantly disadvantageous consequences on the health of farmed animals, via increasing both the susceptibility and the severity of infections like coccidiosis, salmonellosis and Cryptosporidium bailey infections in chicken, Erysipelothrix rhusiopathiae, Brachyspira hyodysentariae, and Escherichia coli infections in pigs, the reactivation of chronic infection by Toxoplasma, and the impairment of vaccination efficacies for Bordetella bronchiseptica and E. rhusiopathiae or with the model antigen ovalbumin in swine (Oswald et al., 2005; Pierron et al., 2016), as well as for fowl cholera and Mareck disease in chickens and/or turkeys (Oswald et al., 2005).

\section{Nephrotoxic Effect}

Renal damages have also been reported after long-term administration of aflatoxins with the symptoms of inflammation, cell necrosis, and toxicosis, which may increase the weight of kidneys and may induce congestion in renal sinusoids. The kidneys are one of the target organs of aflatoxins, and their toxicity is activated by oxidative stress that alters the expression of proline dehydrogenase reducing the proline levels, which induces downstream apoptotic cell death. Moderate focal to diffuse necrosis in the renal tubules and increased renal tubular cells, which may be filled with bile pigments, hyaline, and lipid, with occlusions of their lumens with local edematous changes were reported in the kidneys of aflatoxin-exposed rats ( $\mathrm{Li}$ et al., 2018). In poultry, the toxic effects exerted by $\mathrm{AFB}_{1}$ on renal functions included reduced concentrations of calcium, inorganic phosphate, sodium, and potassium and increased levels of urea, creatinine and uric acid (Yilmaz et al., 2018). In addition, $\mathrm{AFB}_{1}$ was reported to cause severe heart damage with tachycardia, tachypnea and even death, although the exact mechanism of cardiotoxicity has not been completely known.

\section{Reproductive Effects}

Not so long time ago, the harmful effects of aflatoxins on animals did not include any direct impairment of reproduction but indirect effects through other physiological systems have been considered. Nevertheless, more recent animal studies suggested that aflatoxins should also induce direct reproductive toxicity in both male and female animals based on adverse effects to both spermatozoa and oocytes. Following aflatoxin exposure in utero, monitoring growth parameters in baby animals indicated growth retardation, reduced fetal or egg weights and reduced fetal lengths of the offspring animals. In piglets exposed to maternal aflatoxicosis, growth retardation, thymic involution and impaired peripheral immune efficiency were events frequently reported and leading to early death (Mocchegiani et al., 1998), whereas broiler hens exposed to aflatoxin resulted in embryonic mortality and lowered the 
immunity in the progeny chicks (Rawal et al., 2010). In addition, aflatoxins also possess spermatotoxic effects, which have an impact on the morphology and physiology of spermatozoa: $\mathrm{AFB}_{1}$ affects the male reproduction system altering spermatogenesis as well as epididymal and Leydig cell functions, and also reducing the production of testosterone and the fertility in rats, birds and cattle (Agnes and Akbarsha, 2003). In females, $\mathrm{AFB}_{1}$ reduces the fertility of oocytes by the disruption of oocyte maturation through epigenetic modifications as well as oxidative stress, excessive autophagy and apoptosis (Liu et al., 2015). In addition, in poultry, worsening egg production and quality, together with the deposition of aflatoxins residues in the eggs are described in both acute and chronic aflatoxicoses. The lowered egg production was attributed to the aflatoxins' effect on liver metabolism and function as well as liver lesions in layers, to the inhibited synthesis of proteins and lipogenesis, and to decreased feed intake and digestibility (Jia et al., 2016). It is well-known that aflatoxin causes alterations in the carbohydrate metabolism and impairments of the lipid transport, which effects result in decreased glucose levels and reduced lipid accumulations within hepatocytes, as well as pathological alterations in serum biochemistry and of most coagulation factors have been described in poultry, pigs, cattle and rabbits.

\section{Gastrointestinal Dysfunctions}

Aflatoxins modulate and affect the GIT in multiple ways, the most important of which are changes in the gut morphology, the digestive ability or activity of digestive enzymes, intestinal innate immunity and gut microbiota (Mughal et al., 2017). Nevertheless, only few reports are available in this field and the presented data are also controversial in many cases, especially for ruminants. The absorption of aflatoxins across the intestinal barrier is maximal in the upper part of the GIT in nonruminant animals whereas in ruminants, the harmful aflatoxins like $\mathrm{AFB}_{1}$ are transformed to less toxic compounds (e.g., $\mathrm{AFM}_{1}$ ) or to metabolites with similar or even higher toxicity than the parent molecules (e.g., aflatoxicol) (Gallo et al., 2015). Among the overall adverse effects of aflatoxins, the most significant ones are related to the growth of animals and result in reduced performance. Aflatoxins cause reduced feed intake or even feed refusal with a subsequent decrease in body weight gain, which is determined by direct and/or indirect effects of aflatoxins on the nutrient quality, digestibility and/or absorption. During $\mathrm{AFB}_{1}$ exposure, piglets showed reduced weight gain and Japanese quail have shown a reduction in egg weight (Marin et al., 2002). Reduced absorption of nutrients was reported after aflatoxin exposure and, in cattle, this decreased feed efficiency contributed to the observed compromised ruminal function by reducing cellulose digestion, volatile fatty acid production and rumen motility (Zain, 2011). In relation to nutrient digestibility and metabolizable energy, the presence of aflatoxin in dietary was suggested to reduce the apparent digestibility of crude proteins in ducks, to increase amino acid requirements and to reduce energy utilization in terms of net protein utilization and apparent digestible and metabolizable energy in ducks and chickens. Aflatoxins modulate the activity of digestive enzymes but contradictory effects were reported for amylase, trypsin and chymotrypsin activities in pancreas and duodenum with unchanged level of nutrient digestion in the intestine. However, aflatoxins seem to have only moderate affects on or even sometimes do not affect at all the growths of animals through the alteration or modulation of digestive functions (Grenier and Applegate, 2013), even if, in broiler chicks feed with experimental $\mathrm{AFB}_{1}$ diet, impaired growth, major serum biochemistry measures, gut barrier, endogenous loss, and energy and amino acid digestibility were reported (Chen X. et al., 2016). The effects of $\mathrm{AFB}_{1}$ on intestinal epithelium and microbiota were investigated in some in vivo studies in broiler chicken and rodents. The density of the whole intestine was reduced in the case of low $\mathrm{AFB}_{1}$ doses but at higher doses no such changes were recorded, instead the number of apoptotic cells in the jejunum were elevated, jejunal villi presented lower height, and intestinal lesions were observed in duodenum and ileum, with leucocytic and lymphocytic infiltration. Meanwhile, reduced microbial diversity was observed in the colon with adverse effects on lactic acid bacteria versus unchanged proportion of Firmicutes and Bacterioidetes (Robert et al., 2017).

Additional symptoms of aflatoxicosis involved malnutrition. In vitro methods and animal models, predominantly, in piglets and broiler chicks, have showed that $\mathrm{AFB}_{1}$ altered bioavailability and distributions of essential metal ions as zinc, calcium, magnesium and potassium, reduced the activities of lipogenic and amino acid metabolizing enzymes leading to reduced lipogenesis, and reduced serum concentrations of 25-hydroxy vitamin D, 1,25-dihydroxy vitamin $\mathrm{D}$ and calcium, consequently altering renal functions and parathyroid metabolism (Rushing and Selim, 2019).

Finally, aflatoxicosis in horses showed non-specific clinical signs, such as inappetence, depression, fever, tremor, ataxia and cough. Meanwhile, at necropsy, yellow-brown liver with centrilobular necrosis, icterus, hemorrhage, tracheal exudates and brown urine were observed (Caloni and Cortinovis, 2011).

\section{QUALITATIVE AND QUANTITATIVE AFLATOXIN ANALYTICAL METHODS - ECONOMIC SIGNIFICANCE OF ANALYSIS}

Since the massive death of turkeys (Turkey-X deceases) recorded in England in 1960, a wide spectrum of research has been launched and carried out to shed light on the causes of such high mortality (Büchi and Rae, 1969; Rodricks and Stoloff, 1977). Deciphering the factors leading to Turkey-X disease is a fascinating illustration of how a multidisciplinary approach may help us to solve an important animal health problem. The research covered the development of new analytical tools to measure mycotoxins more precisely, the exploration of the physiological and toxicological effects of these harmful compounds as well as the efficient removal of the toxins and setting up to prevent the manifestation of and to cure the disease itself (Forgacs and Carli, 1962). 
Mycotoxins are mainly produced on small grains, cereals such as wheat, barley, oats, rye and triticale or on corn but animal products such as milk, meat, liver or eggs can also be contaminated by mycotoxins at various points of the feed and food chain (Gacem and El Hadj-Khelil, 2016; Udovicki et al., 2018). Because the sampling of feeds and foods for mycotoxin analysis may follow quite different protocols in different laboratories the standardization of these procedures represents a real challenge for analytics. During mycotoxin analysis, extraction and detection are crucially important issues to gain reliable analytical data, which may help us to optimize storage conditions and setting up rules to control mycotoxin production (Yao et al., 2015).

The first step in the analysis is to extract mycotoxins from the sample after correct sampling and sample preparation. The former and traditional extraction methods for aflatoxin analysis gave us a sample matrix in which the HPLC analysis was too complicated to carry out because of the presence of disturbing and interfering components (Kamimura et al., 1985). Later, the clean-up immonoaffinity columns containing gel suspension of monoclonal antibodies gained ground and became popular due its high specificity. The suspension retains the aflatoxin molecules what can be eluted cleanly, free from any disturbing compounds (Borbély et al., 2010; Lai et al., 2014). Another intention is the extraction with different solvents such as carbon tetrachloride $\left(\mathrm{CCl}_{4}\right)$, chlorobenzene $\left(\mathrm{C}_{6} \mathrm{H}_{5} \mathrm{Cl}\right)$, chloroform $\left(\mathrm{CHCl}_{3}\right)$, and dichloromethane $\left(\mathrm{CH}_{2} \mathrm{Cl}_{2}\right)$, methanol and acetonitrile (Sepherd, 2009; Bertuzzi et al., 2012; Sarnoski et al., 2015).

Analytical methods of mycotoxin surveillance are wideranging and may vary within broad limits across countries.
As a result of a community effort having been made to unify surveillance regulations in the European Union, the European Commission (2006) Regulation (EC) No. 401/2006 laid down the requirements for both recovery and precision in different toxin concentration ranges and gives the methodology for the validation of any analytical procedure, making possible to check if it is acceptable for official analysis (EC No. 401/2006). This covers all characteristics required for an analytical method with such a specific sample background, and the list of characteristics ranges from accuracy to measurement uncertainty through the limit of detection (EC No. 401/2006; Sheppard, 2008; Alshannaq and Yae-Hiuk, 2017; Shanakhat et al., 2018).

An overview on the available analytical methods can be given based on the remarkably abundant literature having been published in this field. We have a plethora of quantitative methods ranging from the different types of Thin Layer Chromatograpy-based to different varieties of HPLC to LCMS/MS-based methodologies. In addition, we can also find good performance procedures among semi-quantitative methods like ELISA-based or biosensor-based protocols. Emerging technologies include hyperspectral imaging and aptamer-based biosensors (EC No. 401/2006; Sheppard, 2008; Vidal et al., 2013; Alshannaq and Yae-Hiuk, 2017; Shanakhat et al., 2018).

The performance parameters of different aflatoxin analytical methods are summarized in Table 5. The different methods can be characterized by several parameters such as accuracy, applicability, reproducibility, limit of detection and so on (Sheppard, 2008; Alshannaq and Yae-Hiuk, 2017; Shanakhat et al., 2018). Trucksess and Zhang (2016) argued that all practically useful analytical methods should meet the basic

TABLE 5 | Analytical methods for aflatoxin measurement.

\begin{tabular}{|c|c|c|c|}
\hline Type of method & Technique & LOD & References \\
\hline \multirow[t]{6}{*}{ Quantitative methods } & Thin Layer Chromatography combined with scanner & $\begin{array}{l}0.1 \mu \mathrm{g} / \mathrm{kg} \mathrm{B}_{2} ; \mathrm{G}_{2} ; \mathrm{M}_{1} \\
0.2 \mu / \mathrm{kg} \mathrm{B} \mathrm{B}_{1} ; \mathrm{G}_{1}\end{array}$ & Kamimura et al., 1985 \\
\hline & $\begin{array}{l}\text { High Performance Liquid Chromatography, in combination with } \\
\text { fluorescence detector }\end{array}$ & $0.002 \mu \mathrm{g} / \mathrm{kg}$ & Kilicel et al., 2017 \\
\hline & Liquid Chromatography with Mass Spectrometry & $0.5 \mu \mathrm{g} / \mathrm{kg}$ & Sirhan et al., 2013 \\
\hline & Liquid Chromatography with tandem Mass Spectrometry & $1 \mu \mathrm{g} / \mathrm{kg}$ & $\begin{array}{l}\text { Alsharif et al., 2019; } \\
\text { Ouakhssase et al., } 2019\end{array}$ \\
\hline & $\begin{array}{l}\text { Ultra High Performance Liquid Chromatography with } \\
\text { fluorescence detector }\end{array}$ & $0.02 \mu \mathrm{g} / \mathrm{kg}$ & $\begin{array}{l}\text { Beltrán et al., 2011; Cui } \\
\text { et al., } 2017\end{array}$ \\
\hline & Capillary electrophoresis & $1 \mu \mathrm{g} / \mathrm{kg} 0.1 \mathrm{ng} / \mathrm{g}$ & $\begin{array}{l}\text { Arroyo-Manzanares et al., } \\
\text { 2010; Xiao et al., } 2018\end{array}$ \\
\hline \multirow[t]{5}{*}{ Semi-quantitative methods } & ELISA & $1 \mathrm{ng} / \mathrm{l}$ & Huybrechts, 2011 \\
\hline & Lateral flow tests LFT & $5 \mu \mathrm{g} / \mathrm{kg}$ & Goh et al., 2014, \\
\hline & Direct fluorescence & $5 \mu / \mathrm{kg}$ & Wacoo et al., 2014 \\
\hline & Fluorescence polarization immunoassay & $30 \mathrm{ng} / \mathrm{ml}$ & Maragos, 2009 \\
\hline & Biosensors & $0.05 \mathrm{ml} 0.005 \mu \mathrm{g} / \mathrm{l}$ & $\begin{array}{l}\text { Gurban et al., 2017; Man } \\
\text { et al., } 2017\end{array}$ \\
\hline Indirect methods & Spectroscopy & $4 \mu \mathrm{g} / \mathrm{kg}$ & Wacoo et al., 2014 \\
\hline \multirow[t]{3}{*}{ Emerging technologies } & Hyperspectral imaging & $10 \mu \mathrm{g} / \mathrm{kg}$ & Wang et al., 2014 \\
\hline & Electronic nose & $5 \mu / \mathrm{kg}$ & Ottoboni et al., 2018 \\
\hline & Aptamer-based biosensors ECL & $0.1 \mathrm{pg} / \mathrm{ml}$ & $\begin{array}{l}\text { Shim et al., 2014; Castillo } \\
\text { et al., 2015; Guo et al., } \\
\text { 2016; Jia et al., 2019; } \\
\text { Kordasht et al., 2019; }\end{array}$ \\
\hline
\end{tabular}


guidelines of reproducibility in different laboratory settings. Based on these premises, protocols that are used in different laboratories from sampling to analysis were compiled, and systems relying on certified material samples (CRMs) are also closely related to this.

Currently, a number of HPLC-MS or MS/MS equipment are used world-wide to gain a detailed overview on the mycotoxin spectra in feeds and foods depending on laboratory capabilities (Berthiller et al., 2018). At the same time, ELISA methods and equipment are used for quick mycotoxin measurements (Christoforidou et al., 2015; Xu et al., 2015; Sineque et al., 2017). New developments in this field have been published in the latest literature (Pennington, 2017; Udomkun et al., 2017; Yan et al., 2017). For example, a novel and promising method has been presented to detect aflatoxin $\mathrm{B}_{1}, \mathrm{~B}_{2}$ and ochratoxin $\mathrm{A}$ in rice starting with dispersive liquid-liquid microextraction followed by LC and fluorescence detection (Lai et al., 2014; Adi and Matcha, 2018).

The impact of aflatoxins on human health (Theumer et al., 2018; Omotayo et al., 2019) is far the most important challenge, which we should keep an eye on in the whole feed and food chain (Zheng et al., 2018). This is the reason for why aflatoxin-related research including analytics is flourishing today. Future research should aim at a deeper understanding of the high-complexity and multi-parameter

\section{REFERENCES}

Abdelmotilib, N. M., Hamad, G., and Salem, E. G. (2018). Aflatoxin M1 reduction in milk by a novel combination of probiotic bacterial and yeast strains. Nutr. Food Saf. 8, 83-99. doi: 10.9734/EJNFS/2018/39486

Adi, P. J., and Matcha, B. (2018). Analysis of aflatoxin B1 in contaminated feed, media, and serum samples of Cyprinus carpio L. by high-performance liquid chromatography. Food Qual. Saf. 2, 199-204. doi: 10.1093/fqsafe/fyy013

Agnes, V. F., and Akbarsha, M. A. (2003). Spermatotoxic effect of aflatoxin B1 in the albino mouse. Food Chem. Toxicol. 41, 119-130. doi: 10.1016/S02786915(02)00171-0

Ahlberg, S. H., Joutsjoki, V., and Korhonen, H. J. (2015). Potential of lactic acid bacteria in aflatoxin risk mitigation. Int. J. Food Microbiol. 207, 87-102. doi: 10.1016/j.ijfoodmicro.2015.04.042

Alkhayyat, F., and Yu, J. H. (2014). Upstream regulation of mycotoxin biosynthesis. Adv. Appl. Microbiol. 86, 251-278. doi: 10.1016/B978-0-12-800262-9.00005-6

Alonso, V. A., Monge, M. P., Dalcero, A. M., Keller, K. M., Rosa, C. A., Cavaglieri, L. R., et al. (2009). Contribution of raw materials on dairy cattle feedstuff aflatoxin contamination in central Argentina. Rev. Bras. Med. Vet. 31, 92-99.

Alshannaq, A., and Yae-Hiuk, Y. (2017). Occurence, toxicity and analysis of major mycotoxins in food. Int. J. Environ. Res. Public Health 14:632. doi: 10.3390/ ijerph14060632

Alsharif, A. M. A., Choo, Y. M., and Tan, G. H. (2019). Detection of five mycotoxins in different food matrices in the Malaysian market by using validated liquid chromatography electrospray ionization triple quadrupole mass spectrometry. Toxins 11:E196. doi: 10.3390/toxins11040196

Amaike, S., and Keller, N. P. (2011). Aspergillus flavus. Annu. Rev. Phytopathol. 49, 107-133. doi: 10.1146/annurev-phyto-072910-095221

Amare, M. G., and Keller, N. P. (2014). Molecular mechanisms of Aspergillus flavus secondary metabolism and development. Fungal Genet. Biol. 66, 11-18. doi: 10.1016/j.fgb.2014.02.008

Anfossi, L., Baggiani, C., Giovannoli, C., and Giraudi, G. (2012). "Occurrence of aflatoxin M1 in dairy products," in Aflatoxins - Detection, Measurement and Control, ed. I. Torres-Pacheco, (Rijeka: InTech). processes influencing the aflatoxin contents of feeds and foods. Novel multilateral approaches are definitely needed to control mycotoxins and their disadvantageous agricultural, health care and economic impacts more effectively (Krska et al., 2016; Stadler et al., 2018).

\section{AUTHOR CONTRIBUTIONS}

IP and ZG acquired funding, managed methodology, contributed to writing, reviewing and editing of the manuscript. FP, PS, WP, GP, TG, FG, AS, and ZG contributed to draft preparation, writing, editing and visualization. IP, PS, WP, and FP finalized the manuscript.

\section{FUNDING}

Project no. 2018-1.2.1-NKP-2018-00002 has been implemented with the support provided from the National Research, Development and Innovation Fund of Hungary, financed under the 2018-1.2.1-NKP funding scheme. This project was also supported by Higher Education Institutional Excellence Program of the Ministry of Human Capacities in Hungary, within the framework of the Biotechnology thematic program of the University of Debrecen, Hungary.

Anfossi, L., Di Nardo, F., Giovannoli, C., Passini, C., and Baggiani, C. (2015). Enzyme immunoassay for monitoring aflatoxins in eggs. Food Control 57, 115-121. doi: 10.1016/j.foodcont.2015.04.013

Arroyo-Manzanares, N., Gámiz-Gracia, L., García-Campaña, A. M., SotoChinchilla, J. J., and García-Ayuso, L. E. (2010). On-line preconcentration for the determination of aflatoxins in rice samples by micellar electrokinetic capillary chromatography with laser-induced fluorescence detection. Electrophoresis 13, 2180-2185. doi: 10.1002/elps.201000062

Asemoloye, M. D., Jonathan, S. G., Saddaf, R., Habiba, Z., Okoawo, E. E., and Bello, T. S. (2017). "Incidence and chemical Implications of aflatoxin in streetvended foods," in Aflatoxin-Control, Analysis, Detection and Health Risks, ed. L. Abdulra'Uf, (London: IntechOpen Limited), 153-176. doi: 10.5772/intechopen. 68478

Aslam, N., Rodrigues, I., McGill, D. M., Warriach, H. M., Cowling, A., Haque, A., et al. (2016). Transfer of aflatoxins from naturally contaminated feed to milk of Nili-Ravi buffaloes fed a mycotoxin binder. Anim. Prod. Sci. 56, 1637-1642. doi: 10.1071/AN14909

Assaf, J. C., Atoui, A., Khoury, A. E., Chokr, A., and Louka, N. (2018). A comparative study of procedures for binding of aflatoxin M1 to Lactobacillus rhamnosus GG. Braz. J. Microbiol. 49, 120-127. doi: 10.1016/j.bjm.2017.05.003

Assaf, J. C., Nahle, S., Chokr, A., Louka, N., and El Khoury, A. (2019). Assorted methods for decontamination of aflatoxin M1 in milk using microbial adsorbents. Toxins 11:E304. doi: 10.3390/toxins11060304

Basaran, P., Basaran-Akgul, N., and Oksuz, L. (2008). Elimination of Aspergillus parasiticus from nut surface with low pressure cold plasma (LPCP) treatment. Food Microbiol. 25, 626-632. doi: 10.1016/j.fm.2007.12.005

Battacone, G., Nudda, A., Cannas, A., Cappio Borlino, A., Bomboi, G., and Pulina, G. (2003). Excretion of aflatoxin M1 in milk of dairy ewes treated with different doses of aflatoxin B1. J. Dairy Sci. 86, 2667-2675. doi: 10.3168/jds.S00220302(03)73862-4

Battacone, G., Nudda, A., Palomba, M., Mazzette, A., and Pulina, G. (2009). The transfer of aflatoxin M1 in milk of ewes fed diet naturally contaminated by aflatoxins and effect of inclusion of dried yeast culture in the diet. J. Dairy Sci. 92, 4997-5004. doi: 10.3168/jds.2008-1684 
Battacone, G., Nudda, A., Rassu, S. P., Decandia, M., and Pulina, G. (2012). Excretion pattern of aflatoxin M1 in milk of goats fed a single dose of aflatoxin B1. J. Dairy Sci. 95, 2656-2661. doi: 10.3168/jds.2011-5003

Battilani, P., Rossi, V., Giorni, P., Pietri, A., Gualla, A., Van Der Fels-Klerx, H. J., et al. (2012). Modelling, Predicting and Mapping the Emergence of Aflatoxins in Cereals in the EU Due to Climate Change. Parma: EFSA.

Battilani, P., Toscano, P., Van Der Fels-Klerx, H. J., Moretti, A., Camardo Leggieri, M., Brera, C., et al. (2016). Aflatoxin B1 contamination in maize in Europe increases due to climate change. Sci. Rep. 6, 1-7. doi: 10.1038/srep24328

Beardall, J. M., and Miller, J. D. (1994). "Deseases in humans with mycotoxins as possible causes," in Mycotoxins in Grains. Compounds Other Than Aflatoxins, eds J. D. Miller, and H. L. Trenholm, (St Paul, MN: Egan), 487-539.

Becker-Algeri, T. A., Castagnaro, D., de Bortoli, K., de Souza, C., Drunkler, D. A., and Badiale-Furlong, E. (2016). Mycotoxins in bovine milk and dairy products: a review. J. Food Sci. 81, R544-R552. doi: 10.1111/1750-3841.13204

Beltrán, E., Ibáñeza, M., Sancho, J. V., Cortés, M. Á, Yusàb, V., and Hernández, F. (2011). UHPLC-MS/MS highly sensitive determination of aflatoxins, the aflatoxin metabolite M1 and ochratoxin A in baby food and milk. Food Chem. 126, 737-744. doi: 10.1016/j.foodchem.2010.11.056

Berthiller, F., Cramer, B., Iha, M. H., Krska, R., Lattanzio, V. M. T., MacDonald, S., et al. (2018). Developments in mycotoxin analysis: an update for 2016-2017. World Mycotoxin J. 11, 5-31. doi: 10.3920/WMJ2017.2250

Bertuzzi, T., Rastelli, S., Mulazzi, A., and Pietri, A. (2012). Evaluation and improvement of extraction methods for the analysis of aflatoxins B1, B2, G1 and G2 from naturally contaminated maize. Food Anal. Method 5, 512-519. doi: 10.1007/s12161-011-9274-5

Borbély, M., Sipos, P., Peles, F., and Györi, Z. (2010). Mycotoxin contamination in cereals. J. Agroaliment. Process. Technol. 16, 96-98.

Borreani, G., and Tabacco, E. (2010). The relationship of silage temperature with the microbiological status of the face of corn silage bunkers. J. Dairy Sci. 93, 2620-2629. doi: 10.3168/jds.2009-2919

Bovo, F., Corassin, C. H., and Rosim, R. E. (2015). Efficiency of lactic acid bacteria strains for decontamination of aflatoxin M1 in phosphate buffer saline solution and skimmed milk. Food Bioprocess. Technol. 6, 2230-2234. doi: 10.1007/ s11947-011-0770-9

Bryden, W. L. (2012). Mycotoxin contamination of the feed supply chain: implications for animal productivity and feed security. Anim. Feed Sci. Technol. 173, 134-158. doi: 10.1016/j.anifeedsci.2011.12.014

Büchi, G., and Rae, I. D. (1969). "The structure and chemistry of the aflatoxins," in Aflatoxin. Scientific Background, Control, and Implications, ed. L. A. Goldblatt, (London: Elsevier Inc.), 55-75. doi: 10.1016/b978-0-12-395513-5. 50008-8

Bueno, D. J., Casale, C. H., Pizzolitto, R. P., Salvano, M. A., and Oliver, G. (2007). Physical adsorption of aflatoxin B1 by lactic acid bacteria and Saccharomyces cerevisiae: a theoretical model. J. Food Prot. 70, 2148-2154. doi: 10.4315/0362$028 \mathrm{x}-70.9 .2148$

Caloni, F., and Cortinovis, C. (2011). Toxicological effects of aflatoxins in horses. Vet. J. 188, 270-273. doi: 10.1016/j.tvjl.2010.06.002

Castells, M., Ramos, A. J., Sanchis, V., and Marín, S. (2007). Distribution of total aflatoxins in milled fractions of hulled rice. J. Agric. Food Chem. 55, 2760-2764. doi: 10.1021/jf063252d

Castillo, G., Spinella, K., Poturnayová, A., Šnejdárková, M., Mosiello, L., and Hianik, T. (2015). Detection of aflatoxin B1 by aptamer-based biosensor using PAMAM dendrimers as immobilization platform. Food Control 52, 9-18. doi: 10.1016/j.foodcont.2014.12.008

Cavallarin, L., Tabacco, E., Antoniazzi, S., and Borreani, G. (2011). Aflatoxin accumulation in whole crop maize silage as a result of aerobic exposure. J. Sci. Food Agric. 91, 2419-2425. doi: 10.1002/jsfa.4481

Chen, A. J., Frisvad, J. C., Sun, B. D., Varga, J., Kocsubé, S., Dijksterhuis, J., et al. (2016). Aspergillus section Nidulantes (formerly Emericella): polyphasic taxonomy, chemistry and biology. Stud. Mycol. 84, 1-118. doi: 10.1016/j. simyco.2016.10.001

Chen, X., Naehrer, K., and Applegate, T. J. (2016). Interactive effects of dietary protein concentration and aflatoxin $\mathrm{B} 1$ on performance, nutrient digestibility, and gut health in broiler chicks. Poult. Sci. 95, 1312-1325. doi: 10.3382/ps/ pew022

Christoforidou, S., Malissiova, E., Gortzi, O., and Hadjichristodoulou, C. (2015). Comparative evaluation of ELISA kits' reliability for the aflatoxin M1 determination in goat milk. Eur. Food Res. Technol. 240, 701-706. doi: 10.1007/ s00217-014-2374-x

Chulze, S. (2010). Strategies to reduce mycotoxin levels in maize during storage: a review. Food Addit. Contam. Part A Chem. Anal. Control Expo. Risk. Assess. 27, 651-657. doi: 10.1080/19440040903573032

Corassin, C. H., Bovo, F., Rosim, R. E., and Oliveira, C. A. F. (2013). Efficiency of Saccharomyces cerevisiae and lactic acid bacteria strains to bind aflatoxin M1 in UHT skim milk. Food Cont. 31, 80-83. doi: 10.1016/j.foodcont.2012. 09.033

Council for Agricultural Science and Technology [CAST], (ed.) (2003). "Mycotoxicoses of animals," in Mycotoxins: Risks in Plant, Animal, and Human Systems, Task Force Report No. 139, (Ames, IA: CAST), 58-79.

Crowley, S., Mahony, J., and van Sinderen, D. (2013). Current perspectives on antifungal lactic acid bacteria as natural bio-preservatives. Trends Food Sci. Technol. 33, 93-109. doi: 10.1016/j.tifs.2013.07.004

Cui, X., Muhammad, I., Li, R., Jin, H., Guo, Z., Yang, Y., et al. (2017). Development of a UPLC-FLD method for detection of aflatoxin B1 and M1 in animal tissue to study the effect of curcumin on mycotoxin clearance rates. Front. Pharmacol. 8:650. doi: 10.3389/fphar.2017.00650

Dadzie, M. A., Oppong, A., Ofori, K., Eleblu, J. S., Ifie, E. B., Blay, E., et al. (2019). Distribution of Aspergillus flavus and aflatoxin accumulation in stored maize grains across three agro-ecologies in Ghana. Food Control 104, 91-98. doi: 10.1016/j.foodcont.2019.04.035

Dalié, D., Deschamps, A., and Richard-Forget, F. (2010). Lactic acid bacteria Potential for control of mold growth and mycotoxins: a review. Food Control 21, 370-380. doi: 10.1016/j.foodcont.2009.07.011

Damayanti, E., Istiqomah, L., Saragih, J. E., Purwoko, T., and Sardjono. (2017). Characterization of lactic acid bacteria as poultry probiotic candidates with aflatoxin B1 binding activities. IOP Conf. Series Earth Environ. Sci. 101, 1-9. doi: 10.1088/1755-1315/101/1/012030

D’Angelo, A., Bellino, C., Alborali, G. L., Biancardi, A., Borrelli, A., Capucchio, M. T., et al. (2007). Neurological signs associated with aflatoxicosis in Piedmontese calves. Vet. Res. 160, 698-700. doi: 10.1136/vr.160. 20.698

Davari, E., Mohsenzadeh, M., Mohammadi, G. H., and Rezaeian-Doloei, R. (2015). Characterization of aflatoxigenic Aspergillus flavus and A. parasiticus strain isolates from animal feedstuffs in northeastern Iran. Iran J. Vet. Res. 16, $150-155$.

De Mello, F. R., and Scussel, V. M. (2007). Characteristics of in-shell Brazil nuts and their relationship to aflatoxin contamination: criteria for sorting. J. Agric. Food Chem. 55, 9305-9310. doi: 10.1021/jf071392x

De Mil, T., Devreese, M., De Baere, S., Van Ranst, E. M., De Backer, P., and Croubels, S. (2015). Characterization of 27 mycotoxin binders and the relation with in vitro zearalenone adsorption at a single concentration. Toxins 7, 21-33. doi: 10.3390/toxins7010021

del Palacio, A., Bettucci, L., and Pan, D. (2016). Fusarium and Aspergillus mycotoxins contaminating wheat silage for dairy cattle feeding in Uruguay. Braz. J. Microbiol. 47, 1000-1005. doi: 10.1016/j.bjm.2016.06.004

Deng, J., Zhao, L., Zhang, N. Y., Karrow, N. A., Krumm, C. S., Qi, D. S., et al. (2018). Aflatoxin B1 metabolism: regulation by phase I and II metabolizing enzymes and chemoprotective agents. Mutat. Res. 778, 79-89. doi: 10.1016/j.mrrev.2018. 10.002

Diaz, G. J., Murcia, H. W., and Cepeda, S. M. (2010). Cytochrome P450 enzymes involved in the metabolism of aflatoxin B1 in chickens and quail. Poult. Sci. 89, 2461-2469. doi: 10.3382/ps.2010-00864

Dobolyi, C. S., Sebok, F., Varga, J., Kocsube, S., Szigeti, G., Baranyi, N., et al. (2013). Occurrence of aflatoxin producing Aspergillus flavus isolates in maize kernels in Hungary. Acta Alimentria 42, 451-459. doi: 10.1556/AAlim.42.2013.3.18

Dogi, C. A., Armando, R., Ludueña, R., de Moreno de LeBlanc, A., Rosa, C. A. R., Dalcero, A., et al. (2011). Saccharomyces cerevisiae strains retain their viability and aflatoxin B1 binding ability under gastrointestinal conditions and improve ruminal fermentation. Food Addit. Contam. Part A Chem. Anal. Control Expo. Risk Assess. 28, 1705-1711. doi: 10.1080/19440049.2011.605771

Dogi, C. A., Fochesato, A., Armando, R., Pribull, B., de Souza, M. M. S., da Silva Coelho, I., et al. (2013). Selection of lactic acid bacteria to promote an efficient silage fermentation capable of inhibiting the activity of Aspergillus parasiticus and Fusarium gramineraum and mycotoxin production. J. Appl. Microbiol. 114, 1650-1660. doi: 10.1111/jam.12173 
Dohnal, V., Wu, Q., and Kuca, K. (2014). Metabolism of aflatoxins: key enzymes and interindividual as well as interspecies differences. Arch. Toxicol. 88, 16351644. doi: 10.1007/s00204-014-1312-9

Driehuis, F., Wilkinson, J. M., Jiang, Y., Ogunade, I., and Adesogan, A. T. (2018). Silage review: animal and human health risks from silage. J. Dairy Sci. 1, 4093-4110. doi: 10.3168/jds.2017-13836

EC Regulation, (1881/2016). European Community: Commission Regulation (EC) No 1881/2006 of 19 December 2006 Setting Maximum Levels for Certain Contaminants in Foodstuffs. Available at: https://eur-lex.europa. eu/legal-content/EN/TXT/PDF/?uri=CELEX:02006R1881-20180319\&qid= 1561971754705\&from=IT (accessed June 19, 2019).

Ehrlich, K. C. (2014). Non-aflatoxigenic Aspergillus flavus to prevent aflatoxin contamination in crops: advantages and limitations. Front. Microbiol. 5:50. doi: $10.3389 /$ fmicb. 2014.00050

Ehrlich, K. C., Li, P., Scharfenstein, L., and Chang, P. K. (2010). HypC, the anthrone oxidase involved in aflatoxin biosynthesis. Appl. Environ. Microbiol. 76, 3374-3377. doi: 10.1128/AEM.02495-09

El-Shanawany, A., Eman, A., Mostafa, M., and Barakat, A. (2005). Fungal populations and mycotoxins in silage in Assiut and Sohag governorates in Egypt, with a special reference to characteristic Aspergilli toxins. Mycopathologia 159, 281-289. doi: 10.1007/s11046-004-5494-1

European Commission, (2006). Commission Regulation, (EC) No. 401/2006 Laying Down the Methods of Sampling and Analysis for the Official Control of the Levels of Mycotoxins Infoodstuffs. Available at: http://eurlex.europa.eu/LexUriServ/ LexUriServ.do?uri=OJ:L:2006:070:0012:0034:EN:PDF (accessed June 19, 2019).

Fandohan, P., Zoumenou, D., Hounhouigan, D. J., Marasas, W. F. O., Wingfield, M. J., and Hell, K. (2005). Fate of aflatoxins and fumonisins during the processing of maize into food products in Benin. Int. J. Food Microbiol. 98, 249-259. doi: 10.1016/j.ijfoodmicro.2004.07.007

Ferrero, F., Prencipe, S., Spadaro, D., Gullino, M. L., Cavallarin, L., Piano, S., et al. (2019). Increase in aflatoxins due to Aspergillus section Flavi multiplication during the aerobic deterioration of corn silage treated with different bacteria inocula. J. Dairy Sci. 102, 1176-1193. doi: 10.3168/jds.2018-15468

Fetaih, H. A., Dessouki, A. A., Hassanin, A. I. A., and Tahan, A. S. (2014). Toxopathological and cytogenetic effects of aflatoxin B1 (AFB1) on pregnant rats. Pathol. Res. Pract. 210, 1079-1089. doi: 10.1016/j.prp.2014.06.001

Filazi, A., and Sireli, U. T. (2013). "Occurrence of aflatoxins in food," in Aflatoxins Recent Advances and Future Prospects, ed. M. Razzaghi-Abyaneh, (London: IntechOpen), 143-170. doi: 10.5772/51031

Fink-Gremmels, J. (2008a). Mycotoxins in cattle feed and carry over to dairy milk: a review. Food Addit. Contam. Part A Chem. Anal. Control Expo. Risk Assess. 25, 172-180. doi: 10.1080/02652030701823142

Fink-Gremmels, J. (2008b). The role of mycotoxins in the health and performance of dairy cows. Vet. J. 176, 84-92. doi: 10.1016/j.tvjl.2007.12.034

Fink-Gremmels, J., and van der Merwe, D. (2019). "Mycotoxins in the food chain: contamination of foods of animal origin," in Chemical Hazards in Foods of Animal Origin, ECVPH Food Safety Assurance and Veterinary Public Health No. 7, eds F. J. M. Smulders, I. M. C. M. Rietjens, and M. D. Rose, (Wageningen: Wageningen Academic Publishers), 241-261. doi: 10.3920/978-90-8686-8773_10

Forgacs, J., and Carli, W. T. (1962). Mycotoxicoses. Adv. Vet. Sci. 7, 273-382.

Frazzoli, C., Gherardi, P., Saxena, N., Belluzzi, G., and Mantovani, A. (2017). The hotspot for (global) one health in primary food production: Aflatoxin M1 in dairy products. Front. Public Health 4:294. doi: 10.3389/fpubh.2016.00294

Frisvad, J. C., Hubka, V., Ezekiel, C. N., Hong, S.-B., Nováková, A., Chen, A. J., et al. (2019). Taxonomy of Aspergillus section Flavi and their production of aflatoxins, ochratoxins and other mycotoxins. Stud. Mycol. 93, 1-63. doi: 10. 1016/j.simyco.2018.06.001

Gacem, M. A., and El Hadj-Khelil, A. O. (2016). Toxicology, biosynthesis, biocontrol of aflatoxin and new methods of detection. Asian Pac. J. Trop. Biomed. 6, 808-814. doi: 10.1016/j.apjtb.2016.07.012

Gachara, G. W., Nyamache, A. K., Harvey, J., Gnonlonfin, G. J. B., and Wainaina, J. (2018). Genetic diversity of Aspergillus flavus and occurrence of aflatoxin contamination in stored maize across three agro-ecological zones in Kenya. Agric. Food Sec. 7, 1-10. doi: 10.1186/s40066-018-0202-4

Gallo, A., Bernardes, T. F., Copani, G., Fortunati, P., Gianluca Giuberti, G., Bruschi, S., et al. (2018). Effect of inoculation with Lactobacillus buchneri LB1819 and Lactococcus lactis $\mathrm{O} 224$ on fermentation and mycotoxin production in maize silage compacted at different densities. Anim. Feed Sci. Technol. 246, 36-45. doi: 10.1016/j.anifeedsci.2018.09.009

Gallo, A., Giuberti, G., Frisvad, J. C., Bertuzzi, T., and Nielsen, K. F. (2015). Review on mycotoxin issues in ruminants: occurrence in forages, effects of mycotoxin ingestion on health status and animal performance and practical strategies to counteract their negative effects. Toxins 7, 3057-3111. doi: 10.3390/ toxins7083057

Garon, D., Richard, E., Sage, L., Bouchart, V., Pottier, D., and Lebaill, P. (2006). Mycoflora and multimycotoxin detection in corn silage. J. Agric. Food Chem. 54, 3479-3484. doi: 10.1021/jf060179i

Gherbawy, Y. A., Shebany, Y. M., and Alharthy, H. (2019). Aspergilli and their aflatoxins contamination of poultry and animal feedstuff samples in western region of Saudi Arabia. Sains Malaysiana 48, 765-771. doi: 10.17576/jsm-20194804-08

Gil-Serna, J., Vázquez, C., and Patiño, B. (2019). Genetic regulation of aflatoxin, ochratoxin A, trichothecene, and fumonisin biosynthesis: a review. Int. Microbiol. doi: 10.1007/s10123-019-00084-2 [Epub ahead of print].

Giovati, L., Magliani, W., Ciociola, T., Santinoli, C., Conti, S., and Polonelli, L. (2015). AFM1 in milk: physical, biological, and prophylactic methods to mitigate contamination. Toxins 7, 4330-4349. doi: 10.3390/toxins7104330

Glamočić, D., Polovinski Horvatović, M., Jajić, I., Krstović, S., and Guljaš, D. (2019). Occurrence of aflatoxin B1, ochratoxin A and zearalenone in maize silage in the region of Vojvodina, Serbia. Acta Vet. 69, 106-115. doi: 10.2478/ acve-2019-0007

Gnonlonfin, G. J., Hell, K., Adjovi, Y., Fandohan, P., Koudande, D. O., Mensah, G. A., et al. (2013). A review on aflatoxin contamination and its implications in the developing world: a sub-Saharan African perspective. Crit. Rev. Food Sci. Nutr. 53, 349-365. doi: 10.1080/10408398.2010.535718

Goh, P. H., Zheng, M., and Cvak, B. (2014). A rapid quantitative lateral flow test for the detection of total aflatoxins in maize. Asian Pac. J. Trop. Dis. 4:249. doi: 10.1016/S2222-1808(14)60563-6

Gomah, N. H., Ragab, W. S., and Bullerman, L. B. (2010). Inhibition of fungal growth and aflatoxin B1 production by some Lactobacillus strains. Assiut. J. Agric. Sci. 40, 27-36. doi: 10.1007/s12602-017-9350-2

Gonçalves, B. L., Gonçalves, J. L., Rosim, R. E., Cappato, L. P., Cruz, A. G., Oliveira, C. A. F., et al. (2017). Effects of different sources of Saccharomyces cerevisiae biomass on milk production, composition, and aflatoxin M1 excretion in milk from dairy cows fed aflatoxin B1. J. Dairy Sci. 100, 5701-5708. doi: 10.3168/jds.201612215

González Pereyra, M. L., Alonso, V. A., Sager, R., Morlaco, M. B., Magnoli, C. E., Astoreca, A. L., et al. (2008). Fungi and selected mycotoxins from pre- and postfermented corn silage. J. Appl. Microbiol. 104, 1034-1041. doi: 10.1111/j. 1365-2672.2007.03634.x

González Pereyra, M. L., Chiacchiera, S. M., Rosa, C. A. R., Sager, R., Dalcero, A. M., and Cavaglieri, L. (2011). Comparative analysis of mycobiota and mycotoxins contaminating corn trench silos and silo bags. J. Sci. Food Agric. 91, 1474-1481. doi: $10.1002 /$ jsfa.4336

González Pereyra, M. L., Dogi, C., Torres Lisa, A., Wittouck, P., Ortíz, M., Escobar, F., et al. (2014). Genotoxicity and cytotoxicity evaluation of probiotic Saccharomyces cerevisiae RC016: a 60-day subchronic oral toxicity study in rats. J. Appl. Microbiol. 117, 824-833. doi: 10.1111/jam.12552

Grenier, B., and Applegate, T. (2013). Modulation of intestinal functions following mycotoxin ingestion: meta-analysis of published experiments in animals. Toxins 5, 396-430. doi: 10.3390/toxins5020396

Guengerich, F. P., Cai, H., McMahon, M., Hayes, J. D., Sutter, T. R., Groopman, J. D., et al. (2001). Reduction of aflatoxin B1 dialdehyde by rat and human aldo-keto reductases. Chem. Res. Toxicol. 14, 727-737. doi: 10.1021/tx010005p

Guo, X., Wen, F., Zheng, N., Li, S., Fauconnier, M. L., and Wang, J. (2016). An aptamer-based biosensor for detection of aflatoxin M1. J. Anim. Sci. 94, 1-20. doi: 10.2527/jam2016-0599

Gurban, A. M., Epure, P., Oancea, F., and Doni, M. (2017). Achievements and prospects in electrochemical-based biosensing platforms for aflatoxin M1 detection in milk and dairy products. Sensors 17:2951. doi: 10.3390/s171 22951

Hadavi, E., Feizi, H., and Gheibi, B. (2017). Aflatoxin-contaminated nut separation by applied machinery and processing stages in fresh pistachio processing plant. Front. Microbiol. 8:2404. doi: 10.3389/fmicb.2017.02404 
Hashemi, M., Gholampour Azizi, I., Rezai, Z., and Rouhi, S. (2012). Mycological survey and total aflatoxin analyze in silage from Qaemshahr City (Northern Iran). J. Chem. Health Risks 2, 51-56. doi: 10.22034/jchr.2012.543995

Hassan, Z. U., Khan, M. Z., Khan, A., Javed, I., and Hussain, Z. (2012). Effects of individual and combined administration of ochratoxin A and aflatoxin B1 in tissues and eggs of White Leghorn breeder hens. J. Sci. Food Agric. 92, 1540-1544. doi: 10.1002/jsfa.4740

Hawkins, L. K., Windham, G. L., and Williams, W. P. (2005). Effect of different postharvest drying temperatures on Aspergillus flavus survival and aflatoxin content in five maize hybrids. J. Food Prot. 68, 1521-1524. doi: 10.4315/0362028X-68.7.1521

Helferich, W. G., Garrett, W. N., Hsieh, D. P., and Baldwin, R. L. (1986). Feedlot performance and tissue residues of cattle consuming diets containing aflatoxins. J. Anim. Sci. 62, 691-696. doi: 10.2527/jas1986.623691x

Hell, K., and Mutegi, C. (2011). Aflatoxin control and prevention strategies in key crops of Sub-Saharan Africa. Afr. J. Microbiol. Res. 5, 459-466. doi: 10.5897/ AJMR10.009

Hell, K., Mutegi, C., and Fandohan, P. (2010). "Aflatoxin control and prevetion strategies in maize for Sub-Saharan Africa," in Proceedings of the 10th International Working Conference on Stored Product Protection, Berlin, doi: $10.5073 /$ jka.2010.425.388

Hellevang, K. J. (2013). Grain Drying. Fargo, ND: North Dakota State University.

Herzallah, S., Alshawabkeh, K., and Fataftah, A. A. L. (2008). Aflatoxin decontamination of artificially contaminated feeds by sunlight, $\gamma$-radiation, and microwave heating. J. Appl. Poult. Res. 17, 515-521. doi: 10.3382/japr.2007-00107

Herzallah, S. M. (2013). Eggs and flesh of laying hens fed aflatoxin B1 contaminated diet. Am. J. Agric. Biol. Sci. 8, 156-161. doi: 10.3844/ajabssp.2013.156.161

Herzallah, S. M., Al-Ameiri, N., Al-Dmoor, H., Mosoud, S., and Shawabkeh, K. (2014). Meat and organs quality of broiler chickens fed diet contaminated with B1 Aflatoxin. Glob. Vet. 12, 376-380.

Hojnik, N., Cvelbar, U., Tavcar-Kalcher, G., Walsh, J. L., and Križaj, I. (2017). Mycotoxin decontamination of food: cold atmospheric pressure plasma versus "classic" decontamination. Toxins 9:151. doi: 10.3390/toxins9050151

Hong, S. Y., Roze, L. V., and Linz, J. E. (2013). Oxidative stress-related transcription factors in the regulation of secondary metabolism. Toxins 5, 683-702. doi: $10.3390 /$ toxins 5040683

Hua, S. S. T., Beck, J. J., Sarreal, S. B. L., and Gee, W. (2014). The major volatile compound 2-phenylethanol from the biocontrol yeast, Pichia anomala, inhibits growth and expression of aflatoxin biosynthetic genes of Aspergillus flavus. Mycotoxin Res. 30, 71-78. doi: 10.1007/s12550-0140189-z

Huebner, K. L., Martin, J. N., Weissend, C. J., Holzer, K. L., Parker, J. K., Lakin, S. M., et al. (2019). Effects of a Saccharomyces cerevisiae fermentation product on liver abscesses, fecal microbiome, and resistome in feedlot cattle raised without antibiotics. Sci. Rep. 9:2559. doi: 10.1038/s41598-019-39181-7

Huybrechts, R. (2011). Evaluation of Immunoassay Kits for Aflatoxin Determination in Corn \& Rice. Tervuren: CODA-CERVA Veterinary and Agrochemical Research Centre.

Intanoo, M., Kongkeitkajorn, M. B., Pattarajinda, V., Bernard, J. K., Callaway, T. R., Suriyasathaporn, W., et al. (2018). Isolation and screening of aflatoxindetoxifying yeast and bacteria from ruminal fluids to reduce aflatoxin B1 contamination in dairy cattle feed. J. Appl. Microbiol. 125, 1603-1613. doi: 10.1111/jam.14060

Isikber, A. A., and Athanassiou, C. G. (2015). The use of ozone gas for the control of insects and micro-organisms in stored products. J. Stored Prod. Res. 64B, 139-145. doi: 10.1016/j.jspr.2014.06.006

Ismail, A., Gonçalves, B. L., de Neeff, D. V., Ponzilacqua, B., Coppa, C., Hintzsche, H., et al. (2018). Aflatoxin in foodstuffs: occurrence and recent advances in decontamination. Food Res. Int. 113, 74-85. doi: 10.1016/j.foodres.2018.06.067

Jia, R., Ma, Q., Fan, Y., Ji, C., Zhang, J., Liu, T., et al. (2016). The toxic effects of combined aflatoxins and zearalenone in naturally contaminated diets on laying performance, egg quality and mycotoxins residues in eggs of layers and the protective effect of Bacillus subtilis biodegradation product. Food Chem. Toxicol. 90, 142-150. doi: 10.1016/j.fct.2016.02.010

Jia, Y., Zhou, G., Liu, P., Li, Z., and Yu, B. (2019). Recent development of aptamer sensors for the quantification of aflatoxin B1. Appl. Sci. 9:2364. doi: 10.3390/ app9112364

Jiang, Y., Ogunade, I. M., Kim, D. H., Li, X., Pech-Cervantes, A. A., Arriola, K. G., et al. (2018). Effect of adding clay with or without a Saccharomyces cerevisiae fermentation product on the health and performance of lactating dairy cows challenged with dietary aflatoxin B1. J. Dairy Sci. 101, 3008-3020. doi: $10.3168 /$ jds.2017-13678

Jiang, Y. H., Yang, H. J., and Lund, P. (2012). Effect of aflatoxin B1 on in vitro ruminal fermentation of rations high in alfalfa hay or ryegrass hay. Anim. Feed Sci. Technol. 175, 85-89. doi: 10.1016/j.anifeedsci.2012.03.021

Joannis-Cassan, C., Tozlovanu, M., Hadjeba-Medjdoub, K., Ballet, N., and PfohlLeszkowicz, A. (2011). Binding of zearalenone, aflatoxin B1, and ochratoxin A by yeast-based products: a method for quantification of adsorption performance. J. Food Prot. 74, 1175-1185. doi: 10.4315/0362-028x.jfp-11-023

Jouany, J. P., Yiannikouris, A., and Bertin, G. (2009). "Risk assessment of mycotoxins in ruminants and ruminant products," in Nutritional and Foraging Ecology of Sheep and Goats, eds T. G. Papachristou, Z. M. Parissi, H. Ben Salem, and P. Morand-Fehr, (Zaragoza: CIHEAM), 205-224.

Kabak, B., and Var, I. (2008). Factors affecting the removal of aflatoxin M1 from food model by Lactobacillus and Bifidobacterium strains. J. Environ. Sci. Health B 43, 617-624. doi: 10.1080/03601230802234740

Kamimura, H., Nishijima, M., Yasuda, K., Ushiyama, H., Tabata, S., and Matsumoto, S. (1985). Simple, rapid cleanup method for analysis of aflatoxins and comparison with various methods. J. Assoc. Off. Anal. Chem. 68, 458-461.

Keller, L. A. M., González Pereyra, M. L., Keller, K. M., Alonso, V. A., Oliveira, A. A., Almeida, T. X., et al. (2013). Fungal and mycotoxins contamination in corn silage: monitoring risk before and after fermentation. J. Stored Prod. Res. 52, 42-47. doi: 10.1016/j.jspr.2012.09.001

Keller, N. P. (2019). Fungal secondary metabolism: regulation, function and drug discovery. Nat. Rev. Microbiol. 17, 167-180. doi: 10.1038/s41579-018-0121-1

Kerekes, K., Bonilauri, P., Serraino, A., Giacometti, F., Piva, S., Zambrini, V., et al. (2016). An effective self-control strategy for the reduction of aflatoxin M1 content in milk and to decrease the exposure of consumers. Food Addit. Contam. Part A Chem. Anal. Control. Expo. Risk Assess. 33, 1840-1849. doi: 10.1080/19440049.2016.1241895

Kiessling, K. H., Pettersson, H., Sandholm, K., and Olsen, M. (1984). Metabolism of aflatoxin, ochratoxin, zearalenone, and three trichothecenes by intact rumen fluid, rumen protozoa, and rumen bacteria. Appl. Environ. Microbiol. 47, 1070-1073.

Kilicel, F., Karapinar, H. S., and Cimen, A. (2017). Quantitation of aflatoxins in food materials using HPLC-FLD method. Sci. J. Anal. Chem. 5, 90-97. doi: 10.11648/j.sjac.20170506.11

Klein, P. J., Buckner, R., Kelly, J., and Coulombe, R. A. Jr. (2000). Biochemical basis for the extreme sensitivity of turkeys to aflatoxin B1. Toxicol. Appl. Pharmacol. 165, 45-52. doi: 10.1006/taap.2000.8926

Klein, P. J., Van Vleet, T. R., Hall, J. O., and Coulombe, R. A. Jr. (2002). Biochemical factors underlying the age-related sensitivity of turkeys to aflatoxin B1. Comp. Biochem. Phys. C 132, 193-201. doi: 10.1016/S1532-0456(02)00065-0

Kordasht, H. K., Moosavy, M.-H., Hasanzadeh, M., Soleymani, J., and Mokhtarzadeh, A. (2019). Determination of aflatoxin M1 using aptamer based biosensor on the surface of dendritic fibrous nano-silica functionalized by amine groups. Anal. Methods 11, 3910-3919. doi: 10.1039/C9AY01185D

Kos, J., Hajnal, E. J., Jajić, I., Krstović, S., Mastilović, J., Šarić, B., et al. (2016). Comparison of ELISA, HPLC-FLD and HPLC-MS/MS methods for determination of aflatoxin M1 in natural contaminated milk samples. Acta Chim. Sloven. 63, 747-756. doi: 10.17344/acsi.2016.2451

Krska, R., de Nijs, M., McNerney, O., Pichler, M., Gilbert, J., Edwards, S., et al. (2016). Safe food and feed through an integrated toolbox for mycotoxin management: the MyToolBox approach. World Mycotoxin J. 9, 487-495. doi: 10.3920/WMJ2016.2136

Kuilman, M. E. M., Maas, R. F. M., and Fink-Gremmels, J. (2000). Cytochrome P450-mediated metabolism and cytotoxicity of aflatoxin B1 in bovine hepatocytes. Toxicology 14, 321-327. doi: 10.1016/S0887-2333(00)00025-4

Kuilman, M. E. M., Maas, R. F. M., Judah, D. J., and Fink-Gremmels, J. (1998). Bovine hepatic metabolism of aflatoxin B1. J. Agric. Food Chem. 46, 2707-2713. doi: 10.1021/jf980062x

Kumar, V., Basu, M. S., and Rajendan, T. P. (2008). Mycotoxin research and mycroflora in some commercially important agricultural commodities. Crop Prot. 27, 891-905. doi: 10.1016/j.cropro.2007.12011

Kutz, R. E., Sampson, J. D., Pompeu, L. B., Ledoux, D. R., Spain, J. N., VázquezAñón, M., et al. (2009). Efficacy of Solis, NovasilPlus, and MTB-100 to reduce aflatoxin M1 levels in milk of early to mid lactation dairy cows fed aflatoxin B1. J. Dairy Sci. 92, 3959-3963. doi: 10.3168/jds.2009-2031

Lai, X. W., Sun, D. L., Ruan, C. Q., Zhang, H., and Liu, C. L. (2014). Rapid analysis of aflatoxins $\mathrm{B} 1, \mathrm{~B} 2$, and ochratoxin $\mathrm{A}$ in rice samples using dispersive 
liquid-liquid microextraction combined with HPLC. J. Sep. Sci. 37, 92-98. doi: 10.1002/jssc. 201300970

Larsson, P., Busk, L., and Tjälve, H. (1994). Hepatic and extrahepatic bioactivation and GSH conjugation of aflatoxin B1 in sheep. Carcinogenesis 15, 947-955. doi: 10.1093/carcin/15.5.947

Le Lay, C., Coton, E., Le Blay, G., Chobert, J. M., Haertlé, T., Choiset, Y., et al. (2016). Identification and quantification of antifungal compounds produced by lactic acid bacteria and propionibacteria. Int. J. Food Microbiol. 239, 79-85. doi: 10.1016/j.ijfoodmicro.2016.06.020

Lee, J., Her, J.-Y., and Lee, K.-G. (2015). Reduction of aflatoxins (B1, B2, G1, and G2) in soybean-based model systems. Food Chem. 189, 45-51. doi: 10.1016/j. foodchem.2015.02.013

Lević, J., Gošić-Dondo, S., Ivanović, D., Stanković, S., Krnjaja, V., Bočarov-Stančić, A., et al. (2013). An outbreak of Aspergillus species in response to environmental conditions in Serbia. Pestic. Phytomed. 28, 167-179. doi: 10.2298/pif13031671

Leyva Salas, M., Mounier, J., Valence, F., Coton, M., Thierry, A., and Coton, E. (2017). Antifungal microbial agents for food biopreservation A review. Microorganisms 5, 1-37. doi: 10.3390/microorganisms503 0037

Li, H., Liu, L., Zhang, S., Cui, W., and Lv, J. (2012). Identification of antifungal compounds produced by Lactobacillus casei AST18. Curr. Microbiol. 65, 156161. doi: 10.1007/s00284-012-0135-2

Li, H., Xing, L., Zhang, M., Wang, J., and Zheng, N. (2018). The toxic effects of aflatoxin B1 and aflatoxin M1 on kidney through regulating L-proline and downstream apoptosis. Biomed. Res. Int. 2018:9074861. doi: 10.1155/2018/ 9074861

Liew, W. P. P., Nurul-Adilah, Z., Than, L. T. L., and Mohd-Redzwan, S. (2018). The binding efficiency and interaction of Lactobacillus casei Shirota toward aflatoxin B1. Front. Microbiol. 9:1503. doi: 10.3389/fmicb.2018.01503

Liu, J., Sui, Y., Wisniewski, M., Droby, S., and Liu, Y. (2013). Review: utilization of antagonistic yeasts to manage postharvest fungal diseases of fruit. Int. J. Food Microbiol. 167, 153-160. doi: 10.1016/j.ijfoodmicro.2013. 09.004

Liu, J., Wang, Q., Han, J., Xiong, B., and Sun, S. (2015). Aflatoxin B1 is toxic to porcine oocyte maturation. Mutagenesis 30, 527-535. doi: 10.1093/mutage/ gev015

Liu, N., Wang, J. Q., Jia, S. C., Chen, Y. K., and Wang, J. P. (2018). Effect of yeast cell wall on the growth performance and gut health of broilers challenged with aflatoxin B1 and necrotic enteritis. Poult. Sci. 97, 477-484. doi: 10.3382/ps/ pex342

Lozano, M. C., and Diaz, G. J. (2006). Microsomal and cytosolic biotransformation of aflatoxin B1 in four poultry species. Br. Poult. Sci. 47, 734-741. doi: 10.1080/ 00071660601084390

Lüthy, J., Zweifel, U., and Schlatter, C. H. (1980). Metabolism and tissue distribution of [14C] aflatoxin B1 in pigs. Food Cosmet. Toxicol. 18, 253-256. doi: 10.1016/0015-6264(80)90103-0

Ma, Z. X., Amaro, F. X., Romero, J. J., Pereira, O. G., Jeong, K. C., and Adesogan, A. T. (2017). The capacity of silage inoculant bacteria to bind aflatoxin B1 in vitro and in artificially contaminated corn silage. J. Dairy Sci. 100, 7198-7210. doi: $10.3168 /$ jds.2016-12370

MacLachlan, D. J. (2011). Estimating the transfer of contaminants in animal feedstuffs to livestock tissues, milk and eggs: a review. Anim. Prod. Sci. 51, 1067-1078. doi: 10.1071/AN11112

Madden, U. A., and Stahr, H. M. (1995). Retention and distribution of aflatoxin in tissues of chicks fed aflatoxin-contaminated poultry rations amended with soil. Vet. Hum. Toxicol. 37, 24-29.

Magan, N., and Aldred, D. (2007). Post-harvest control strategies: minimizing mycotoxins in the food chain. Int. J. Food Microbiol. 119, 131-139. doi: 10.1016/ j.ijfoodmicro.2007.07.034

Magan, N., Hope, R., Cairns, V., and Aldred, D. (2003). Post-harvest fungal ecology: impact of fungal growth and mycotoxin accumulation in stored grain. Eur. J. Plant Pathol. 109, 723-730. doi: 10.1023/A:1026082425177

Magan, N., Medina, A., and Aldred, D. (2011). Possible climate change effects on mycotoxin contamination of food crops pre- and postharvest. Plant Pathol. 60, 150-163. doi: 10.1111/j.1365-3059.2010.02412.x

Magnoli, A. P., Rodriguez, M. C., González Pereyra, M. L., Poloni, V. L., Peralta, M. F., Nilson, A. J., et al. (2017). Use of yeast (Pichia kudriavzevii) as a novel feed additive to ameliorate the effects of aflatoxin $\mathrm{B} 1$ on broiler chicken performance. Mycotoxin Res. 33, 273-283. doi: 10.1007/s12550-017-0285-y

Man, Y., Liang, G., Lee, A., and Pan, L. (2017). Recent advances in mycotoxin determination for food monitoring via microchip. Toxins 9:324. doi: 10.3390/ toxins 9100324

Mannaa, M., and Kim, K. D. (2017). Influence of temperature and water activity on deleterious fungi and mycotoxin production during grain storage. Mycobiology 45, 240-254. doi: 10.5941/MYCO.2017.45.4.240

Manoza, F. S., Mushongi, A. A., Harvey, L., Wainaina, J., Wanjuki, I., Ngeno, R., et al. (2017). Potential of using host plant resistance, nitrogen and phosphorus fertilizers for reduction of Aspergillus flavus colonization and aflatoxin accumulation in maize in Tanzania. J. Crop Prot. 93, 98-105. doi: 10.1016/j.cropro.2016.11.021

Mansfield, M. A., and Kuldau, G. A. (2007). Microbiological and molecular determination of mycobiota in fresh and ensiled maize silage. Mycologia 99, 269-278. doi: 10.3852/mycologia.99.2.269

Maragos, C. (2009). Fluorescence polarization immunoassay of mycotoxins: a review. Toxins 2, 196-207. doi: 10.3390/toxins 1020196

Marin, D. E., Taranu, I., Bunaciu, R. P., Pascale, F., Tudor, D. S., Avram, N., et al. (2002). Changes in performance, blood parameters, humoral and cellular immune responses in weanling piglets exposed to low doses of aflatoxin. J. Anim. Sci. 80, 1250-1257. doi: 10.2527/2002.8051250x

Markov, K., Mihaljević, B., Domijan, A.-M., Pleadin, J., Delaš, F., and Frece, J. (2015). Inactivation of aflatoxigenic fungi and the reduction of aflatoxin B1 in vitro and in situ using gamma irradiation. Food Control 54, 79-85. doi: 10.1016/j.foodcont.2015.01.036

Masoero, F., Gallo, A., Moschini, M., Piva, G., and Diaz, D. (2007). Carryover of aflatoxin from feed to milk in dairy cows with low or high somatic cell counts. Animal 1, 1344-1350. doi: 10.1017/S1751731107000663

Mateo, E. M., Gil-Serna, J., Patiño, B., and Jiménez, M. (2011). Aflatoxins and ochratoxin A in stored barley grain in Spain and impact of PCR-based strategies to assess the occurrence of aflatoxigenic and ochratoxigenic Aspergillus spp. Int. J. Food Microbiol. 149, 118-126. doi: 10.1016/j.ijfoodmicro.2011.06.006

Matumba, L., Van Poucke, C., Ediage, E. N., Jacobs, B., and De Saeger, S. (2015). Effectiveness of hand sorting, flotation/washing, dehulling and combinations thereof on the decontamination of mycotoxin-contaminated white maize. Food Addit. Contam. Part A 32, 960-969. doi: 10.1080/19440049.2015.1029535

Meissonnier, G. M., Pinton, P., Laffitte, J., Cossalter, A., Gong, Y. Y., Wild, C. P., et al. (2008). Immunotoxicity of aflatoxin B1: impairment of the cell-mediated response to vaccine antigen and modulation of cytokine expression. Toxicol. Appl. Pharmacol. 231, 142-149. doi: 10.1016/j.taap.2008.04.004

Micco, C., Miraglia, M., Onori, R., Brera, C., Mantovani, A., Ioppolo, A., et al. (1988). Long-term administration of low doses of mycotoxins to poultry. 1. Residues of aflatoxin B1 and its metabolites in broilers and laying hens. Food Addit. Contam. 5, 303-308. doi: 10.1080/02652038809373708

Miller, D. M., and Wilson, D. M. (1994). "Veterinary diseases related to Aflatoxins," in The Toxicology of Aflatoxins: Human Health. Veterinary, and Agricultural Significance, eds D. L. Eaton, and J. D. Groopman, (San Diego, CA: Academic Press, Inc.), 347-364. doi: 10.1016/b978-0-12-228255-3.50021-0

Miller, J. D. (2008). Mycotoxins in small grains and maize: old problems, new challenges. Food Addit. Contam. Part A Chem. Anal. Control Expo Risk Assess. 25, 219-230. doi: 10.1080/02652030701744520

Misra, N. N., Yadav, B., Roopesh, M. S., and Jo, C. (2019). Cold plasma for effective fungal and mycotoxin control in foods: mechanisms, inactivation effects, and applications. Compr. Rev. Food. Sci. F 18, 106-120. doi: 10.1111/1541-4337. 12398

Mocchegiani, E., Corradi, A., Santarelli, L., Tibaldi, A., Deangelis, E., Borghetti, P., et al. (1998). Zinc, thymic endocrine activity and mitogen responsiveness (PHA) in piglets exposed to maternal aflatoxicosis B1 and G1. Vet. Immunol. Immunopathol. 62, 245-260. doi: 10.1016/s0165-2427(98)00073-7

Mohamed, N. F., El-Dine, R. S. S., Kot, M. A. M., and Saber, A. (2015). Assessing the possible effect of gamma irradiation on the reduction of aflatoxin B1, and on the moisture content in some cereal grains. Am. J. Biomed. Sci. 7, 33-39. doi: 10.5099/aj150100033

Moreau, M., Lescure, G., Agoulon, A., Svinareff, P., Orange, N., and Feuilloley, M. (2013). Application of the pulsed light technology to mycotoxin degradation and inactivation. J. Appl. Toxicol. 33, 357-363. doi: 10.1002/jat.1749 
Muck, R. E., Nadeau, E. M. G., McAllister, T. A., Contreras-Govea, F. E., Santos, M. C., and Kung, L. Jr. (2018). Silage review: recent advances and future uses of silage additives. J. Dairy Sci. 101, 3980-4000. doi: 10.3168/jds.2017-13839

Mughal, M. J., Peng, X., Kamboh, A. A., Zhou, Y., and Fang, J. (2017). Aflatoxin $\mathrm{B} 1$ induced systemic toxicity in poultry and rescue effects of selenium and zinc. Biol. Trace Elem. Res. 178, 292-300. doi: 10.1007/s12011-016-0923-9

Mutungi, C., Lamuka, P., Arimi, S., Gathumbi, J., and Onyango, C. (2008). The fate of aflatoxins during processing of maize into muthokoi - A traditional Kenyan food. Food Control. 19, 714-721. doi: 10.1016/j.foodcont.2007.07.011

Mwakinyali, S. E., Ding, X., Ming, Z., Tong, W., Zhang, Q., and Li, P. (2019). Recent development of aflatoxin contamination biocontrol in agricultural products. Biol Control. 128, 31-39. doi: 10.1016/j.biocontrol.2018.09.012

Neme, K., and Mohammed, A. (2017). Mycotoxin occurrence in grains and the role of postharvest management as a mitigation strategies. A review. Food Control 78, 412-425. doi: 10.1016/j.foodcont.2017.03.012

Nidhina, N., Bhavya, M. L., Bhaskar, N., Muthukumar, S. P., and Murthy, P. S. (2017). Aflatoxin production by Aspergillus flavus in rumen liquor and its implications. Food Control 71, 26-31. doi: 10.1016/j.foodcont.2016.05.051

Niessen, L., Bechtner, J., Fodil, S., Taniwaki, M. H., and Vogel, R. F. (2018). LAMP-based group specific detection of aflatoxin producers within Aspergillus section Flavi in food raw materials, spices, and dried fruit using neutral red for visible-light signal detection. Int. J. Food Microbiol. 266, 241-250. doi: 10.1016/ j.ijfoodmicro.2017.12.013

Ogunade, I. M., Arriola, K. G., Jiang, Y., Driver, J. P., Staples, C. R., and Adesogan, A. T. (2014). Effects of 3 sequestering agents on milk aflatoxin M1 concentration and the performance and immune status of dairy cows fed diets artificially contaminated with aflatoxin B1. J. Dairy Sci. 9, 6263-6273. doi: 10.3168/jds. 2016-10905

Ogunade, I. M., Martinez-Tuppia, C., Queiroz, O. C. M., Jiang, Y., Drouin, P., $\mathrm{Wu}, \mathrm{F}$., et al. (2018). Silage review: mycotoxins in silage: occurrence, effects, prevention, and mitigation. J. Dairy Sci. 101, 4034-4059. doi: 10.3168/jds.201713788

Oguz, H., and Parlat, S. (2005). Effects of dietary mannanoligosaccharide on performance of Japanese quail affected by aflatoxicosis. S. Afr. J. Anim. Sci. 34, 144-148. doi: 10.4314/sajas.v34i3.3957

Ojuri, O. T., Ezekiel, C. N., Eskola, M. K., Šarkanj, B., Babalola, A. D., Sulyok, M., et al. (2019). Mycotoxin co-exposures in infants and young children consuming household- and industrially-processed complementary foods in Nigeria and risk management advice. Food Control 98, 312-322. doi: 10.1016/j.foodcont. 2018.11.049

Omotayo, O. P., Omotayo, A. O., Babalola, O. O., and Mwanza, M. (2019). Comparative study of aflatoxin contamination of winter and summer ginger from the North West Province of South Africa. Toxicol. Rep. 6, 489-495. doi: 10.1016/j.toxrep.2019.05.011

Ortatatli, M., and Oguz, H. (2001). Ameliorative effects of dietary clinoptilolite on pathological changes in broiler chickens during aflatoxicosis. Res. Vet. Sci. 71, 59-66. doi: 10.1053/rvsc.2001.0487

Oswald, I. P., Marin, D. E., Bouhet, S., Pinton, P., Taranu, I., and Accensi, F. (2005). Immunotoxicological risk of mycotoxins for domestic animals. Food Addit. Contam. 22, 354-360. doi: 10.1080/02652030500058320

Ottoboni, M., Pinotti, L., Tretola, M., Giromini, C., Fusi, E., Rebucci, R., et al. (2018). Combining E-nose and lateral flow immunoassays (LFIAs) for rapid occurrence/co-occurrence aflatoxin and fumonisin detection in maize. Toxins 10:416. doi: 10.3390/toxins10100416

Ouakhssase, A., Chahid, A., Choubbane, H., Aitmazirt, A., and Addi, E. A. (2019). Optimization and validation of a liquid chromatography/tandem mass spectrometry (LC-MS/MS) method for the determination of aflatoxins in maize. Heliyon 5:e01565. doi: 10.1016/j.heliyon.2019.e01565

Pantaya, D., Morgavi, D. P., Silberberg, M., Martin, C., Wiryawan, K. G., and Boudra, H. (2014). Low $\mathrm{pH}$ enhances rumen absorption of aflatoxin B1 and ochratoxin A in sheep. Glob. Vet. 13, 227-232. doi: 10.5829/idosi.gv.2014.13.02. 84118

Pasha, T. N. (2008). Detoxification of aflatoxin by yeast sludge in the feed of dairy cattle and its impact on increased milk production. Int. J. Agro Vet. Med. Sci. 2, 18-26.

Pasikatan, M. C., and Dowell, F. E. (2001). Sorting systems based on optical methods for detecting and removing seeds infested internally by insects or fungi: a review. Appl. Spectrosc. Rev. 36, 399-416. doi: 10.1081/ASR-100107719
Paterson, R. R. M., and Lima, N. (2011). Further mycotoxin effects from climate change. Food Res. Int. 44, 2555-2566. doi: 10.1016/j.foodres.2011.05.038

Patil, H., Shah, N. G., Hajare, S. N., Gautam, S., and Kumar, G. (2019). Combination of microwave and gamma irradiation for reduction of aflatoxin $\mathrm{B} 1$ and microbiological contamination in peanuts (Arachis hypogaea L.). World Mycotoxin J. 12, 269-280. doi: 10.3920/WMJ2018.2384

Patras, A., Julakanti, S., Yannam, S., Bansode, R. R., Burns, M., and Vergne, M. J. (2017). Effect of UV irradiation on aflatoxin reduction: a cytotoxicity evaluation study using human hepatoma cell line. Mycotoxin Res. 33, 343-350. doi: 10.1007/s12550-017-0291-0

Peng, W.-X., Marchal, J. L. M., and van der Poel, A. F. B. (2018). Review article. Strategies to prevent and reduce mycotoxins for compound feed manufacturing. Anim. Feed Sci. Tech. 237, 129-153. doi: 10.1016/j.anifeedsci. 2018.01.017

Pennington, J. A. (2017). Aflatoxin M1 in milk. Food Control 76, 127-138. doi: 10.1016/j.foodcont.2017.01.008

Pereyra, C. M., Alonso, V. A., Rosa, C. A. R., Chiacchiera, S. M., Dalcero, A. M., and Cavaglieri, R. R. (2008). Gliotoxin natural incidence and toxigenicity of Aspergillus fumigatus isolated from maize silage and ready dairy cattle feed. World Mycotoxin J. 1, 457-462. doi: 10.3920/WMJ2007.1012

Pfliegler, W. P., Pusztahelyi, T., and Pócsi, I. (2015). Mycotoxins - Prevention and decontamination by yeasts. J. Basic Microbiol. 55, 805-818. doi: 10.1002/jobm. 201400833

Pier, A. C. (1992). Major biological consequences of aflatoxicosis in animal production. J. Anim. Sci. 70, 3964-3967. doi: 10.2527/1992.70123964x

Pierides, M., El-Nezami, H., Peltonen, K., Salminen, S., and Ahokas, J. (2000). Ability of dairy strains of lactic acid bacteria to bind aflatoxin M1 in a food model. J. Food Prot. 63, 645-650. doi: 10.4315/0362-028x-63.5.645

Pierron, A., Alassane-Kpembi, I., and Oswald, I. (2016). Impact of mycotoxin on immune response and consequences for pig health. Anim. Nutr. 2, 63-68. doi: 10.1016/j.aninu.2016.03.001

Pizzolitto, R. P., Armando, M. R., Combina, M., Cavaglieri, L. R., Dalcero, A. M., and Salvano, M. A. (2012). Evaluation of Saccharomyces cerevisiae strains as probiotic agent with aflatoxin B1 adsorption ability for use in poultry feedstuffs. J. Environ. Sci. Health B 47, 933-941. doi: 10.1080/03601234.2012.706558

Plaizier, J. C., Danesh Mesgaran, M., Derakhshani, H., Golder, H., Khafipour, E., Kleen, J. L., et al. (2018). Review: enhancing gastrointestinal health in dairy cows. Animal. 12, s399-s418. doi: 10.1017/S1751731118001921

Poppy, G. D., Rabiee, A. R., Lean, I. J., Sanchez, W. K., Dorton, K. L., and Morley, P. S. (2012). A meta-analysis of the effects of feeding yeast culture produced by anaerobic fermentation of Saccharomyces cerevisiae on milk production of lactating dairy cows. J. Dairy Sci. 95, 6027-6041. doi: 10.3168/jds.2012-5577

Prandini, A., Tansini, G., Sigolo, S., Filippi, L., Laporta, M., and Piva, G. (2009). On the occurrence of aflatoxin M1 in milk and dairy products. Food Chem. Toxicol. 47, 984-991. doi: 10.1016/j.fct.2007.10.005

Prencipe, S., Siciliano, I., Gatti, C., Gullino, M. L., Garibaldi, A., and Spadaro, D. (2018). Chestnut drying is critical in determining Aspergillus flavus growth and aflatoxin contamination. Toxins 10:530. doi: 10.3390/toxins10120530

Pusztahelyi, T., Holb, I. J., and Pócsi, I. (2015). Secondary metabolites in fungusplant interactions. Front. Plant Sci. 6:573. doi: 10.3389/fpls.2015.00573

Queiroz, O. C. M., Kim, S. C., and Adesogan, A. T. (2012). Effect of treatment with a mixture of bacteria and fibrolytic enzymes on the quality and safety of corn silage infested with different levels of rust. J. Dairy Sci. 95, 5285-5291. doi: $10.3168 /$ jds.2012-5431

Rawal, S., Kim, J. E., and Coulombe, R. A. Jr. (2010). Aflatoxin B1 in poultry: toxicology, metabolism and prevention. Res. Vet. Sci. 89, 325-331. doi: 10.1016/ j.rvsc.2010.04.011

Reddy, K. R. N., and Salleh, B. (2010). A preliminary study on the occurrence of Aspergillus spp. and aflatoxin B1 in imported wheat and barley in Penang, Malaysia. Mycotoxin Res. 26, 267-271. doi: 10.1007/s12550-010-0065-4

Reverberi, M., Ricelli, A., Zjalic, S., Fabbri, A. A., and Fanelli, C. (2010). Natural functions of mycotoxins and control of their biosynthesis in fungi. Appl. Microbiol. Biotechnol. 87, 899-911. doi: 10.1007/s00253-010-2657-5

Richard, E., Heutte, N., Bouchart, V., and Garon, D. (2009). Evaluation of fungal contamination and mycotoxin production in maize silage. Anim. Feed Sci. Technol. 148, 309-320. doi: 10.1016/j.anifeedsci.2008.02.004

Richard, J. L. (2008). Discovery of aflatoxins and significant historical features. Toxin Rev. 27, 171-201. doi: 10.1080/15569540802462040 
Robert, H., Payros, D., Pinto, P., Théodorou, V., Mercier-Bonin, M., and Oswald, I. P. (2017). Impact of mycotoxins on the intestine: are mucus and microbiota new targets? J. Toxicol. Environ. Health B Crit. Rev. 20, 249-275. doi: 10.1080/ 10937404.2017.1326071

Rodricks, J. V., and Stoloff, L. (1977). "Aflatoxin residues from contaminated feed in edible tissues of food-producing animals," in Mycotoxins in Human and Animal Health, eds J. V. C. Rodricks, W. Hesseltine, and M. A. Mehlman, (Park Forest South, ILL: Patholox Publishers), 67-79.

Rodrigues, R. O., Ledoux, D. R., Rottinghaus, G. E., Borutova, R., Averkieva, O., and McFadden, T. B. (2019). Feed additives containing sequestrant clay minerals and inactivated yeast reduce aflatoxin excretion in milk of dairy cows. J. Dairy Sci. 102, 6614-6623. doi: 10.3168/jds.2018-16151

Rodríguez-Blanco, M., Ramos, A. J., Prim, M., Sanchis, V., and Marín, S. (2019). Usefulness of the analytical control of aflatoxins in feedstuffs for dairy cows for the prevention of aflatoxin M1 in milk. Mycotoxin Res. doi: 10.1007/s12550019-00362-y [Epub ahead of print].

Roze, L. V., Hong, S. Y., and Linz, J. E. (2013). Aflatoxin biosynthesis: current frontiers. Annu. Rev. Food Sci. Technol. 4, 293-311. doi: 10.1146/annurev-food083012-123702

Rushing, B. R., and Selim, M. I. (2019). Aflatoxin B1: a review on metabolism, toxicity, occurrence in food, occupational exposure, and detoxification methods. Food Chem. Toxicol. 124, 81-100. doi: 10.1016/j.fct.2018.11.047

Sarnoski, V. J., Billingsley, V. E., Johnson, J. V., and O'keefe, S. F. (2015). Effect of solvent on aflatoxin content in extracts of virginia type peanut skins. J. Nutr. Health 1, 75-83. doi: 10.3153/JFHS15007

Schmidt, P., Novins, C. O., Junges, D., Almeida, R., and de Souza, C. M. (2015). Concentration of mycotoxins and chemical composition of corn silage: a farm survey using infrared thermography. J. Dairy Sci. 98, 6609-6619. doi: 10.3168/ jds.2014-8617

Sen, Y., Onal-Ulusoy, B., and Mutlu, M. (2019). Detoxification of hazelnuts by different cold plasmas and gamma irradiation treatments. Innov. Food Sci. Emerg. Technol. 54, 252-259. doi: 10.1016/j.ifset.2019.05.002

Sepherd, G. S. (2009). Aflatoxin analysis at the beginning of the twenty-first century. Anal. Bioanal. Chem. 395, 1215-1224. doi: 10.1007/s00216-009-2857-y

Serra, M. S., Pulles, M. B., Mayanquer, F. T., Vallejo, M. C., Rosero, M. I., Ortega, J. M., et al. (2018). Evaluation of the use of gamma radiation for reduction of aflatoxin $\mathrm{B} 1$ in corn (Zea mays) used in the production of feed for broiler chickens. J. Agric. Chem. Environ. 7, 21-33. doi: 10.4236/jacen.2018. 71003

Shanakhat, H., Sorrentino, A., Raiola, A., Romano, A., Masi, P., and Cavella, S. (2018). Current methods for mycotoxins analysis and innovative strategies for their reduction in cereals: an overview. J. Sci. Food Agric. 98, 4003-4013. doi: $10.1002 /$ jsfa. 8933

Sheppard, G. S. (2008). Determination of mycotoxins in human foods. Chem. Soc. Rev. 37, 2468-2477. doi: 10.1039/b713084h

Shi, H., Ileleji, K., Stroshine, R. L., Keener, K., and Jensen, J. L. (2017). Reduction of aflatoxin in corn by high voltage atmospheric cold plasma. Food Bioprocess Technol. 10:1042. doi: 10.1007/s11947-0171873-8

Shi, H., Stroshine, R. L., and Ileleji, K. (2014). "Aflatoxin reduction in corn by cleaning and sorting," in Proceedings of the 2014 ASABE Annual International Meeting Paper, St. Joseph, MI. doi: 10.1007/s11947-017-1873-8

Shim, W.-B., Mun, H., Joung, H.-A., Ofori, J. A., Chung, D.-H., and Kim, M.G. (2014). Chemiluminescence competitive aptamer assay for the detection of aflatoxin B1 in corn samples. Food control 36, 30-35. doi: 10.1016/j.foodcont. 2013.07.042

Siciliano, I., Spadaro, D., Prelle, A., Vallauri, D., Cavallero, M. C., Garibaldi, A., et al. (2016). Use of cold atmospheric plasma to detoxify hazelnuts from aflatoxins. Toxins 8:125. doi: 10.3390/toxins 8050125

Sineque, A. R., Macuamule, C. L., and Dos Anjos, F. R. (2017). Aflatoxin B1 contamination in chicken livers and gizzards from industrial and small abattoirs, measured by ELISA technique in Maputo, Mozambique. Int. J. Environ. Res. Public Health 14:951. doi: 10.3390/ijerph1409 0951

Sirhan, A. Y., Tan, G. H., and Wong, R. C. S. (2013). Determination of aflatoxins in food using liquid chromatography coupled with electrospray ionization quadrupole time of flight mass spectrometry (LC-ESIQTOF-MS/MS). Food Control 31, 35-44. doi: 10.1016/j.foodcont.2012. 09.016
Siwela, A. H., Siwela, M., Matindi, G., Dube, S., and Nziramasanga, N. (2005). Decontamination of aflatoxin-contaminated maize by dehulling. J. Sci. Food Agric. 85, 2535-2538. doi: 10.1002/jsfa.2288

Śliżewska, K., and Smulikowska, S. (2011). Detoxification of aflatoxin B1 and change in microflora pattern by probiotic in vitro fermentation of broiler feed. J. Anim. Feed Sci. 20, 300-309. doi: 10.22358/jafs/66187/2011

Stadler, D., Sulyok, M., Schuhmacher, R., Berthiller, F., and Krska, R. (2018). The contribution of lot-to-lot variation to the measurement uncertainty of an LCMS-based multi-mycotoxin assay. Anal. Bioanal. Chem. 410, 4409-4418. doi: 10.1007/s00216-018-1096-5

Stasiewicz, M. J., Falade, T. D. O., Mutuma, M., Mutiga, S. K., Harvey, J. J. W., Fox, G., et al. (2017). Multi-spectral kernel sorting to reduce aflatoxins and fumonisins in Kenyan maize. Food Control. 78, 203-214. doi: 10.1016/j. foodcont.2017.02.038

Storm, I. M. L. D., Rasmussen, R. R., and Rasmussen, P. H. (2014). Occurrence of pre- and post-harvest mycotoxins and other secondary metabolites in Danish maize silage. Toxins 6, 2256-2269. doi: 10.3390/toxins6082256

Sukmawati, D., Setyaningsih, A., Handayani, K. T., Rahayu, S., Rustam, Y., Moersilah, M., et al. (2018). Isolation and characterization of aflatoxigenic Aspergillus spp. from maize of livestock feed from Bogor. IOP Conf. Ser. Mater. Sci. Eng. 434, 1-8. doi: 10.1088/1757-899X/434/1/012105

Sultana, N., Iftikhar, S., Hanif, N. Q., and Tahira, I. (2017). Natural incidence of Aspergillus mycoflora and mycotoxins in fresh and ensiled maize fodder. Pakistan J. Zool. 49, 475-480. doi: 10.17582/journal.pjz/2017.49.2.475.480

Tao, F., Yao, H., Hruska, Z., Burger, L. W., Rajasekaran, K., and Bhatnagar, D. (2018). Recent development of optical methods in rapid and non-destructive detection of aflatoxin and fungal contamination in agricultural products. Trends Anal. Chem. 100, 65-81. doi: 10.1016/j.trac.2017.12.017

Tejada-Castañeda, Z. I., Avila-Gonzalez, E., Casaubon-Huguenin, M. T., Cervantes-Olivares, R. A., and Vásquez-Peláez, C. (2008). Biodetoxification of aflatoxin-contaminated chick feed. Poult. Sci. 87, 1569-1576. doi: 10.3382/ps. 2007-00304

Theumer, M. G., Henneb, Y., Khoury, L., Snini, S. P., Tadrist, S., Canlet, C., et al. (2018). Genotoxicity of aflatoxins and their precursors in human cells. Toxicol. Lett. 287, 100-107. doi: 10.1016/j.toxlet.2018.02.007

Thieu, N. Q., and Pettersson, H. (2009). Zearalenone, deoxynivalenol and aflatoxin $\mathrm{B} 1$ and their metabolites in pig urine as biomarkers for mycotoxin exposure. Mycotox. Res. 25, 59-66. doi: 10.1007/s12550-009-0009-z

Tiwari, B. W., Brennan, C. S., Curran, T., Gallagher, E., Cullen, P. J., and O' Donnell, C. P. (2010). Application of ozone in grain processing. J. Cereal Sci. 51, 248-255. doi: 10.1016/j.jcs.2010.01.007

Torlak, E., Akata, I., Erci, F., and Uncu, A. T. (2016). Use of gaseous ozone to reduce aflatoxin B1 and microorganisms in poultry feed. J. Stored Prod. Res. 68, 44-49. doi: 10.1016/j.jspr.2016.04.003

Trevisani, M., Farkas, Z., Serraino, A., Zambrini, A. V., Pizzamiglio, V., Giacometti, F., et al. (2014). Analysis of industry-generated data. Part 1: a baseline for the development of a tool to assist the milk industry in designing sampling plans for controlling aflatoxin M1 in milk. Food Addit. Contam. Part A Chem. Anal. Control Expo. Risk Assess. 31, 1246-1256. doi: 10.1080/19440049.2014.925587

Trucksess, M. W., and Zhang, K. (2016). Cutting-edge techniques for mycotoxin analysis. J. AOAC Int. 99, 835-836. doi: 10.5740/jaoacint.16-0109

Tulayakul, P., Dong, K., and Kumagai, S. (2006). Organ differences in microsomes and cytosol metabolism of Aflatoxin B1 in piglets. Toxicol. Environ. Chem. 88, 479-487. doi: 10.1080/02772240600662203

Udomkun, P., Wiredu, A. N., Nagle, M., Müller, J., Vanlauwe, B., and Bandyopadhyay, R. (2017). Innovative technologies to manage aflatoxins in foods and feeds and the profitability of application - A review. Food Control 6, 127-138. doi: 10.1016/j.foodcont.2017.01.008

Udovicki, B., Audenaert, K., De Saeger, S., and Rajkovic, A. (2018). Overview on the mycotoxins incidence in Serbia in the period 2004-2016. Toxins 10:279. doi: 10.3390/toxins 10070279

Upadhaya, S. D., Sung, H. G., Lee, C. H., Lee, S. Y., Kim, S. W., Kyung, J., et al. (2009). Comparative study on the aflatoxin B1 degradation ability of rumen fluid from Holstein steers and Korean native goats. J. Vet. Sci. 10, 29-34. doi: 10.4142/jvs.2009.10.1.29

Usman, M., Javed, M. R., Mehmood, M. A., Huma, T., and Ijaz, A. (2019). Isolation of aflatoxigenic Aspergillus flavus from animal-feed and exploration of the genetic basis of aflatoxin biosynthesis. Pak. Vet. J. (in press). doi: 10.29261/ pakvetj/2019.078 
van Asselt, E. D., van der Fels-Klerx, H. J., Marvin, H. J. P., van Bokhorst-van, H., and Nierop Groot, M. (2017). Overview of food safety hazards in the European dairy supply chain. Compr. Rev. Food Sci. Food Saf. 16, 59-75. doi: 10.1111/1541-4337.12245

Varga, J., Baranyi, N., Chandrasekaran, M., Vágvölgyi, C. S., and Kocsubé, S. (2015). Mycotoxin producers in the Aspergillus genus: an update. Acta Biol. Szeged 59, 151-167.

Variane, A. C. F., Santos, F. C., Castro, F. F., Barbosa-Tessmann, I. P., Santos, G. T., and Santos Pozza, M. S. (2018). The occurrence of aflatoxigenic Aspergillus spp. in dairy cattle feed in Southern Brazil. Braz. J. Microbiol. 49, 919-928. doi: 10.1016/j.bjm.2018.05.005

Vasishth, P. D., and Bavarva, A. (2016). Image processing method for embedded optical peanut sorting. Int. J. Image Graph. Signal Process. 8, 20-27. doi: 10. 5815/ijigsp.2016.02.03

Veldman, A., Meijst, J. A. C., Borggreve, G. J., and Heeres-van der Tol, J. J. (1992). Carry-over of aflatoxin from cow's food to milk. Anim. Prod. 55, 163-168. doi: 10.1017/S0003356100037417

Verheecke, C., Liboz, T., and Mathieu, F. (2016). Microbial degradation of aflatoxin B1: current status and future advances. Int. J. Food Microbiol. 237, 1-9. doi: 10.1016/j.ijfoodmicro.2016.07.028

Vidal, J. C., Bonel, L., Ezquerra, A., Hernández, S., and Castillo, J. R. (2013). Electrochemical affinity biosensors for detection of mycotoxins: a review. Biosens. Bioelectron 49, 146-158. doi: 10.1016/j.bios2013. 05.008

Vila-Donat, P., Marín, S., Sanchis, V., and Ramos, A. J. (2018). A review of the mycotoxin adsorbing agents, with an emphasis on their multi-binding capacity, for animal feed decontamination. Food Chem. Toxicol. 114, 246-259. doi: 10. 1016/j.fct.2018.02.044

Villers, P. (2014). Aflatoxins and safe storage. Front. Microbiol. 5:158. doi: 10.3389/ fmicb.2014.00158

Virdis, S., Scarano, C., Spanu, V., Ibba, I., and De Santis, E. P. L. (2014). A survey on Aflatoxin M1 content in sheep and goat milk produced in Sardinia region, Italy (2005-2013). Ital. J. Food Saf. 3:4517. doi: 10.4081/ijfs.2014. 4517

Wacoo, A. P., Wendiro, D., Vuzi, P. C., and Hawumba, J. F. (2014). Methods for detection of aflatoxins in agricultural food crops. J. Appl. Chem. 2014:706291. doi: 10.1155/2014/706291

Wang, B., Mahoney, N. E., Pan, Z., Khir, R., Wu, B., Ma, H., et al. (2016). Effectiveness of pulsed light treatment for degradation and detoxification of aflatoxin B1 and B2 in rough rice and rice bran. Food Control 59, 461-467. doi: 10.1016/j.foodcont.2015.06.030

Wang, H., Li, W., Muhammad, I., Sun, X., Cui, X., and Cheng, P. (2018). Biochemical basis for the age-related sensitivity of broilers to aflatoxin B1. Toxicol. Mech. Methods 28, 361-368. doi: 10.1080/15376516.2018.142 8258

Wang, Y., Zhang, H., Yan, H., Yin, C., Liu, Y., Xu, Q., et al. (2018). Effective biodegradation of aflatoxin B1 using the Bacillus licheniformis (BL010) strain. Toxins 10:497. doi: 10.3390/toxins10120497

Wang, W., Heitschmidt, G. W., Ni, X., Windham, W. R., Hawkins, S., and Chu, X. (2014). Identification of aflatoxin B1 on maize kernel surfaces using hyperspectral imaging. Food Control 42, 78-86. doi: 10.1016/j.foodcont.2014. 01.038

Weaver, M. A., and Abbas, H. K. (2019). Field displacement of aflatoxigenic Aspergillus flavus strains through repeated biological control applications. Front. Microbiol. 10:1788. doi: 10.3389/fmicb.2019.01788

Westlake, K., Mackie, R. I., and Dutton, M. F. (1989). In vitro metabolism of mycotoxins by bacterial, protozoal and ovine ruminal fluid preparations. Anim. Feed Sci. Tech. 25, 169-178. doi: 10.1016/0377-8401(89) 90117-X
Wu, F., Bhatnagar, D., Bui-Klimke, T., Carbone, I., Hellmich, R., Munkvold, G., et al. (2011). Climate changes impacts on mycotoxin risks in US maize. World Mycotoxin J. 4, 79-93. doi: 10.3920/WMJ2010.1246

Xiao, M. W., Bai, X. L., Liu, Y. M., Yang, L., and Liao, X. (2018). Simultaneous determination of trace aflatoxin B1 and ochratoxin A by aptamer-based microchip capillary electrophoresis in food samples. J. Chromatogr. A 1569, 222-228. doi: 10.1016/j.chroma.2018.07.051

Xu, F., Ren, K., Yang, Y., Gio, J., Ma, G., Liu, Y., et al. (2015). Food safety special issue: immunoassay of chemical contaminants in milk: a review. J. Integr. Agric. 14, 2282-2295. doi: 10.1016/S2095-3119(15)61121-2

Yan, M., Li, A., Liang, G., and Ligang, L. (2017). Recent advances in mycotoxin determination for food monitoring via microchip. Toxins 9:324. doi: 10.3390/ toxins 9100324

Yao, H., Hruska, Z., and Di Mavungu, J. D. (2015). Aflatoxins in maize and other crops. Developments in detection and determination of aflatoxins. World Mycotoxin J. 8, 181-191. doi: 10.3920/WMJ2014

Yiannikouris, A., and Jouany, J. P. (2002). Mycotoxins in feeds and their fate in animals: a review. Anim. Res. 51, 81-99. doi: 10.1051/animres:2002012

Yilmaz, S., Kaya, E., Karaca, A., and Karatas, B. (2018). Aflatoxin B1 induced renal and cardiac damage in rats: protective effect of lycopene. Res. Vet. Sci. 119, 268-275. doi: 10.1016/j.rvsc.2018.07.007

Yu, J. (2012). Current understanding on aflatoxin biosynthesis and future perspective in reducing aflatoxin contamination. Toxins 4, 1024-1057. doi: 10.3390/toxins4111024

Yunus, A. W., Razzazi-Fazeli, E., and Bohm, J. (2011). Aflatoxin B1 in affecting broiler's performance, immunity, and gastrointestinal tract: a review of history and contemporary issues. Toxins 3, 566-590. doi: 10.3390/toxins306 0566

Zain, M. E. (2011). Impact of mycotoxins on humans and animals. J. Saudi Chem. Soc. 15, 129-144. doi: 10.1016/j.jscs.2010.06.006

Zheng, N., Zhang, H., Li, S., Wang, J., Liu, J., Ren, H., et al. (2018). Lactoferrin inhibits aflatoxin B1- and aflatoxin M1-induced cytotoxicity and DNA damage in Caco-2, HEK, Hep-G2, and SK-N-SH cells. Toxicon 150, 77-85. doi: 10.1016/ j.toxicon.2018.04.017

Zhu, F. (2018). Effect of ozone treatment on the quality of grain products. Food Chem. 264, 358-366. doi: 10.1016/j.foodchem.2018.05.047

Zhu, W., Wei, Z., Xu, N., Yang, F., Yoon, I., Chung, Y., et al. (2017). Effects of Saccharomyces cerevisiae fermentation products on performance and rumen fermentation and microbiota in dairy cows fed a diet containing low quality forage. J. Anim. Sci. Biotechnol. 8:36. doi: 10.1186/s40104-0170167-3

Zielińska, K. J., and Fabiszewska, A. U. (2018). Improvement of the quality of maize grain silage by a synergistic action of selected lactobacilli strains. World J. Microbiol. Biotechnol. 34, 1-9. doi: 10.1007/s11274-017-2400-9

Zulkifli, N. A., and Zakaria, L. (2017). Morphological and molecular diversity of Aspergillus from corn grain used as livestock feed. HAYATI J. Biosci. 24, 26-34. doi: 10.1016/j.hjb.2017.05.002

Conflict of Interest: The authors declare that the research was conducted in the absence of any commercial or financial relationships that could be construed as a potential conflict of interest.

Copyright (c) 2019 Peles, Sipos, Győri, Pfliegler, Giacometti, Serraino, Pagliuca, Gazzotti and Pócsi. This is an open-access article distributed under the terms of the Creative Commons Attribution License (CC BY). The use, distribution or reproduction in other forums is permitted, provided the original author(s) and the copyright owner(s) are credited and that the original publication in this journal is cited, in accordance with accepted academic practice. No use, distribution or reproduction is permitted which does not comply with these terms. 